\title{
Elucidating the impact of charge selective contact in halide perovskite through impedance spectroscopy
}

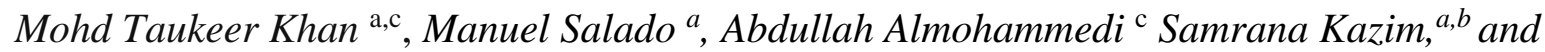 \\ Shahzada Ahmad, , $^{*}$
}

\author{
${ }^{a}$ BCMaterials-Basque Center for Materials, Applications and Nanostructures, Martina Casiano, \\ UPV/EHU Science Park, Barrio Sarriena s/n, Leioa 48940, Spain. \\ ${ }^{b}$ IKERBASQUE, Basque Foundation for Science, Bilbao, 48013, Spain. \\ ${ }^{c}$ Department of Physics, Faculty of Science, Islamic University of Madinah, Prince Naifbin \\ Abdulaziz, Al Jamiah, Madinah 42351, Kingdom of Saudi Arabia. \\ Tel: +34 946128811 Email: shahzada.ahmad@bcmaterials.net
}

\begin{abstract}
The electron and hole selective contact (SC) play a pivotal role in the performance of perovskite solar cells. In order to separate the interfacial phenomenon from bulk, the influence of charge SC was elucidated, by means of impedance spectroscopy. The specific role played by $\mathrm{TiO}_{2}$ and Spiro$O M e T A D$ as electron and hole SC in perovskite solar cells was investigated at short circuit condition at different temperatures. We have probed $\mathrm{MAPbI}_{3}$ and $\left(\mathrm{FAPbI}_{3}\right)_{0.85}\left(\mathrm{MAPbBr}_{3}\right)_{0.15}$ and elucidated parameters such as charge carrier mobility, recombination resistance, time constant and charge carrier kinetics in perovskite layer and at the interface of perovskite/SC. Charge carrier mobility in mixed perovskite was found to be nearly two order of magnitude higher as compared to $\mathrm{MAPbI}_{3}$. Moreover, the carrier mobility in devices with only electron $\mathrm{SC}$ was found to be higher as compared only hole SC. The charge accumulation at $\mathrm{TiO}_{2} /$ perovskite/Spiro-OMeTAD interfaces were studied via frequency dependent capacitance, revealing higher charge accumulation at perovskite/Spiro-OMeTAD than at $\mathrm{TiO}_{2} /$ perovskite interface. By performing varying temperature frequency dependent capacitance measurements the distribution of density of state within the bandgap of the perovskites, the emission rate of electrons from the trap states and traps activation energy was determined.
\end{abstract}

Keywords: electron selective contact; hole selective contact; density of state; charge carrier mobility; impedance spectroscopy. 


\section{Introduction}

The field of perovskite solar cells was initiated by the use of model $\mathrm{MAPbI}_{3}$, and its success paved the way for new formulations by the means of compositional engineering of perovskites. ${ }^{1}$ Tweaking of halide anion and/or organic cation allowed to push the efficiency as well as stability. ${ }^{2}$ Power conversion efficiencies as high as $25.2 \%$ have been reported at laboratory scale ${ }^{3}$, which is on par with other matured thin film PV technologies. The realization of perovskite for solar cells application was due to its intriguing opto-electrical properties, which led, to its exploitation in other opto-electrical devices such as lasing, ${ }^{4} \mathrm{X}$-ray, OLEDs, ${ }^{5}$ and photodiodes. ${ }^{6}$ Despite its unparalleled performance, the perovskites solar cells suffer from several key issues such as anomalous $J-V$ hysteresis, electrical instability, non-radiative recombination losses, and environmental instability. The primary cause for $J-V$ hysteresis are intrinsic defects present in the perovskites layers and charge accumulation at interfaces. ${ }^{7-10}$ The plausible reason for the charge accumulation at the interface can be unbalanced electron and hole mobility which allows charge to be accumulated at the perovskite/electron selective contact (ESC) and perovskite/hole selective contact (HSC) interface. ${ }^{11}$

In the past we have reported unbalance charge extraction along with its charge injection time scale and also noted charge accumulation at ESC/perovskite interface. ${ }^{12}$ The defect states present in the bulk of perovskite effect the charge accumulation near the interface. Furthermore, the presence of defects in the bulk of perovskites further act as trapping center for charge carriers, which in turn cause non-radiative losses and decreases charge carrier's lifetimes leading to deterioration in the device performance. Moreover, the presence of inorganic part suggest mixed conductivity, with contribution from both electronic and ionic conductivity. The ion migration was also speculated to be one of the reason for low long term photovoltaic behavior under stress condition or at $V_{\text {oc. }}{ }^{13,14}$ Similarly cathode materials such as silver or gold was reported to be found at anode side, which travelled all the way through hole transport materials and perovskites. This diffusion of metallic contact into the active material is a loss, and this process can activate intensely by thermal process. ${ }^{15}$ Apart from all these, the undesirable process in which dopant ions mainly $\mathrm{Li}^{+}$(used in HSC) can diffuses into perovskite matrix and destabilized the stoichiometry due to its hydrophillicity. ${ }^{16}$ Despite the numerous studies reported in the literature, the meticulous device physics and role of ESC and HSC in perovskite solar cells are still ambiguous. Consequently, for the assessment and understanding of selective contacts and electrical parameters of device needs 
to be investigated to unravel the charge kinetics, will allow perovskites solar cells for further optimization.

Impedance spectroscopy is a sensitive technique, which can be utilized to probe the dynamic electrical properties occurring inside the perovskite solar cells. It can provide the information about the various resistive and capacitive process such as charge transport, recombination losses, interfacial charge accumulation etc. Due to a large variety of equivalent circuits available in literature and overlapping of various capacitive process e.g. overlapping of accumulation and geometrical capacitance at intermediate frequencies, the interpretation of the derived fitted parameters are still obscure. Herein, to elucidate the underlying various electrical and physical process which control the PV performance, we have selected two standard organohalide perovskites $\left[\mathrm{MAPbI}_{3}\right.$ and $\left(\mathrm{FAPbI}_{3}\right)_{0.85}\left(\mathrm{MAPbBr}_{3}\right)_{0.15}$. In order to separate the interfacial and bulk related process and decode the role of each SC for solar cells, the devices with and without selective contact was also probed. Photo-induced carriers change the polarizability of perovskite layer which allows three orders of increment in low frequency dielectric constant of $\mathrm{MAPbI}_{3}{ }^{17}$ Moreover, illumination also leads to a uniform lattice expansion in perovskite which can further modify the electrical properties. ${ }^{18}$ Besides, the ferroelectric nature of $\mathrm{MAPbI}_{3}$ is also influenced by charge injection at applied bias due to build-up ion-induced structural fluctuations and polarization. ${ }^{19,20}$ To avoid such phenomena, we have performed the measurements in dark and at short circuit (i.e. no DC bias) condition. The configuration of each device is represented in Table 1 along with the classification of the type of structure used for both perovskite, and the schematics of the devices are shown in Figure 1.

Table 1. Device configurations of $\mathrm{MAPbI}_{3}$ and $\left(\mathrm{FAPbI}_{3}\right)_{0.85}\left(\mathrm{MAPbBr}_{3}\right)_{0.15}$ perovskites.

\begin{tabular}{|c|c|c|c|c|}
\hline \multicolumn{2}{|l|}{$\mathrm{MAPbI}_{3}$} & \multirow{2}{*}{$\begin{array}{c}\begin{array}{c}\text { Type of } \\
\text { structure }\end{array} \\
\text { only perovskite }\end{array}$} & \multicolumn{2}{|c|}{$\left(\mathrm{FAPbI}_{3}\right)_{0.85}\left(\mathrm{MAPbBr}_{3}\right)_{0.15}$} \\
\hline $\mathrm{FTO} / \mathrm{MAPbI}_{3} / \mathrm{Au}$ & Type A & & FTO/mix-Pero/Au & $A^{\prime}$ \\
\hline $\mathrm{FTO} / \mathrm{MAPbI}_{3} / \mathrm{HTM} / \mathrm{Au}$ & Type B & $\begin{array}{l}\text { perovskite with } \\
\text { HTM }\end{array}$ & $\begin{array}{l}\text { FTO/mix- } \\
\text { Pero/HTM } \\
\text { /Au }\end{array}$ & $\mathrm{B}^{\prime}$ \\
\hline $\begin{array}{l}\mathrm{FTO} / \mathrm{c}-\mathrm{TiO}_{2} / \mathrm{m}-\mathrm{TiO}_{2} / \\
\mathrm{MAPbI}_{3} / \mathrm{Au}\end{array}$ & Type C & $\begin{array}{l}\text { perovskite with } \\
\text { ETM }\end{array}$ & $\begin{array}{l}\mathrm{FTO} / \mathrm{c}-\mathrm{TiO}_{2} / \mathrm{m}- \\
\mathrm{TiO}_{2} / \mathrm{mix}-\mathrm{Pero} / \mathrm{Au}\end{array}$ & $\mathrm{C}^{\prime}$ \\
\hline $\begin{array}{l}\mathrm{FTO} / \mathrm{c}-\mathrm{TiO}_{2} / \mathrm{m}-\mathrm{TiO}_{2} / \\
\mathrm{MAPbI}_{3} / \mathrm{HTM} / \mathrm{Au}\end{array}$ & Type D & Full device & $\begin{array}{l}\mathrm{FTO} / \mathrm{c}-\mathrm{TiO}_{2} / \mathrm{m}- \\
\mathrm{TiO}_{2} / \mathrm{mix}^{-} \\
\text {Pero/HTM/Au }\end{array}$ & $\mathrm{D}^{\prime}$ \\
\hline
\end{tabular}




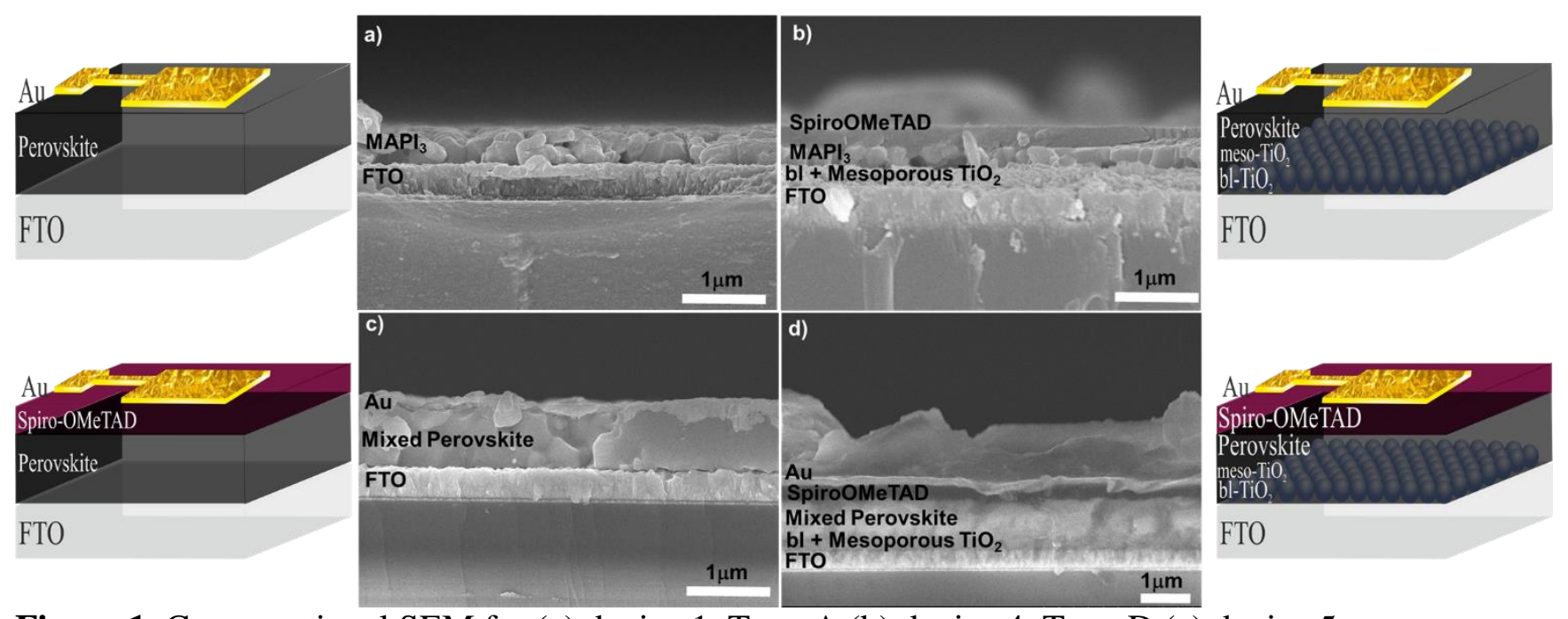

Figure 1. Cross sectional SEM for (a) device 1, Type A (b) device 4, Type D (c) device 5, Type A' and (d) device, Type D'. Here, bl refers to $\mathrm{TiO}_{2}$ blocking layer.

\section{Results and discussions}

Figure 1 shows the cross-sectional view of scanning electron micrograph for fabricated devices to gaze the thickness of different layers. The type of architect used can be deducted from the micrographs.

The role of $\mathrm{TiO}_{2}$ (compact + mesoporous) and Spiro-OMeTAD as electron and hole SC on charge transfer and recombination process inside the perovskite solar cells was systematically analyzed via impedance spectroscopy. Figure 2a-d and Figure 3a-d display the impedance arch for full device or without selective contact in the temperature range $300-360 \mathrm{~K}$. We noted the appearance of semicircle and the radius of semicircle decreases with an increase in temperature for all curves. It can be deducted from Figures that the full device (type D \& D') has high resistance whereas the devices without any charge extraction layers (type A and \& $A^{\prime}$ ) showed least resistance. From Figure $2 b$ and $2 c$, it can be concluded that the main resistive component in device is due to ESC (i.e. $\mathrm{TiO}_{2}$ ). The measurements based on $\mathrm{MAPbI}_{3}$, and without selective contact (type $\mathrm{A}, \mathrm{B}, \mathrm{C}$ ) display a single semicircle, whereas the full device fabricated from $\mathrm{MAPbI}_{3}$ (Type D) showed two semicircles at higher temperature $(>330 \mathrm{~K})$, attributed to the double relaxation behavior, one at the interface, while the other in bulk of perovskite. The semicircle at higher frequency (HF) is associated to the charge transfer and recombination through perovskite/charge selective contacts mainly perovskite/Spiro-OMeTAD interfaces, ${ }^{46,53,54}$ and the semicircle at low frequency (LF) 
attributed to charge carrier (e-h) recombination, dielectric relaxation, and ionic migration in perovskite layer. $^{21,46,53,55-57}$ The HF part is missing for devices without SC (type A \& A'), plausibly the interfacial recombination process in such devices is fast enough and it did not showed in the measured frequency range ( $2 \mathrm{MHz}$ ). We have noted, the selective contact play an important role to minimize the interfacial recombination. The LF arc in the impedance spectra (IS) of devices based on mixed cations (except device type $\mathrm{A}^{\prime}$ ) is clearly visible as compared to $\mathrm{MAPbI}_{3}$ devices. This implies that, the ionic migration and dielectric relaxation in $\mathrm{MAPbI}_{3}$ perovskites is slow enough to show its signature in the LF region while in case of mixed perovskite these effects are more prominent than $\mathrm{MAPbI}_{3}$.

The equivalent circuit shown in Figure 2e-f and Figure 3e-g were used to model the experimental impedance results of each devices. Each circuit represents a series resistance $\mathrm{R}_{1}$ ascribed to the contact resistance of electrical wire and fluorine doped tin oxide (FTO) based electrode which was deduced from high frequency intercept on the real-axis. ${ }^{22-24}$ The value of $\mathrm{R}_{1}$ used to model the IS are given in supporting information (SI) and are in the range of $7-20 \Omega$. The LF part of the IS was modeled using $\mathrm{I}^{\mathrm{st}} \mathrm{RC}$ element shown in equivalent circuit, where $\mathrm{R}_{2}$ and $\mathrm{C}_{1}$ are related to the charge $(\mathrm{e}-\mathrm{h})$ recombination resistance $\left(\mathrm{R}_{\mathrm{rec}}\right)$ and dielectric relaxation capacitance of perovskite layer. The second $\mathrm{RC}$ element in equivalent circuit is attributed to the interfacial charge transfer resistance $\left(\mathrm{R}_{3}\right)$ and capacitance due to the charge accumulation at the interface of perovskite layer and SC. ${ }^{25}$ This aid is responsible for the features appearing at high frequency in the Nyquist plot. ${ }^{26-28}$ As discussed above the LF response is related to the ionic migration and dielectric relaxation process in perovskite layer while HF element describe the interfacial charge transfer and recombination process at perovskite and charge SC interface. To improve the fitting quality, constant phase elements (CPE) were used instead of ideal capacitors. CPEs are typically used to model the behavior of the capacitance in an inhomogeneous layer or interfaces due to roughness or variations in the thickness. ${ }^{29,30}$ The time constant for both interfacial and bulk phenomenon were estimated from the fitting parameters of corresponding semicircles and we noted that the bulk relaxation process take place in the time scale of $10^{-4} s$ for all devices. On the contrary, the interfacial time varies between $10^{-1} s-10^{-3} s$ depending on the device architects used. The device with HSC (Spiro-OMeTAD) showed lowest time constant while the device with ESC $\left(\mathrm{c}-\mathrm{TiO}_{2}\right)$ gave highest time constant value. The high charge accumulation at HSC is due to high concentration of $\mathrm{MA}^{+}$cation as compared to $\mathrm{I}^{-},{ }^{42}$ which led to higher charge accumulation at HSC 
interface as compared to ESC interface (Figure 8). While, the device fabricated from $\left(\mathrm{FAPbI}_{3}\right)_{0.85}\left(\mathrm{MAPbBr}_{3}\right)_{0.15}$, the interfacial components reveals slightly higher degree of charge accumulation at $\mathrm{TiO}_{2} /\left(\mathrm{FAPb}_{3}\right)_{0.85}\left(\mathrm{MAPbBr}_{3}\right)_{0.15}$ interface as compared to $\mathrm{TiO}_{2} / \mathrm{MAPbI}_{3}$ interface. From the fitting parameters, we noted that the recombination resistance in $\left(\mathrm{FAPbI}_{3}\right)_{0.85}\left(\mathrm{MAPbBr}_{3}\right)_{0.15}$ is higher as compared to $\mathrm{MAPbI}_{3}$. This is due to lower recombination current in mixed perovskite.
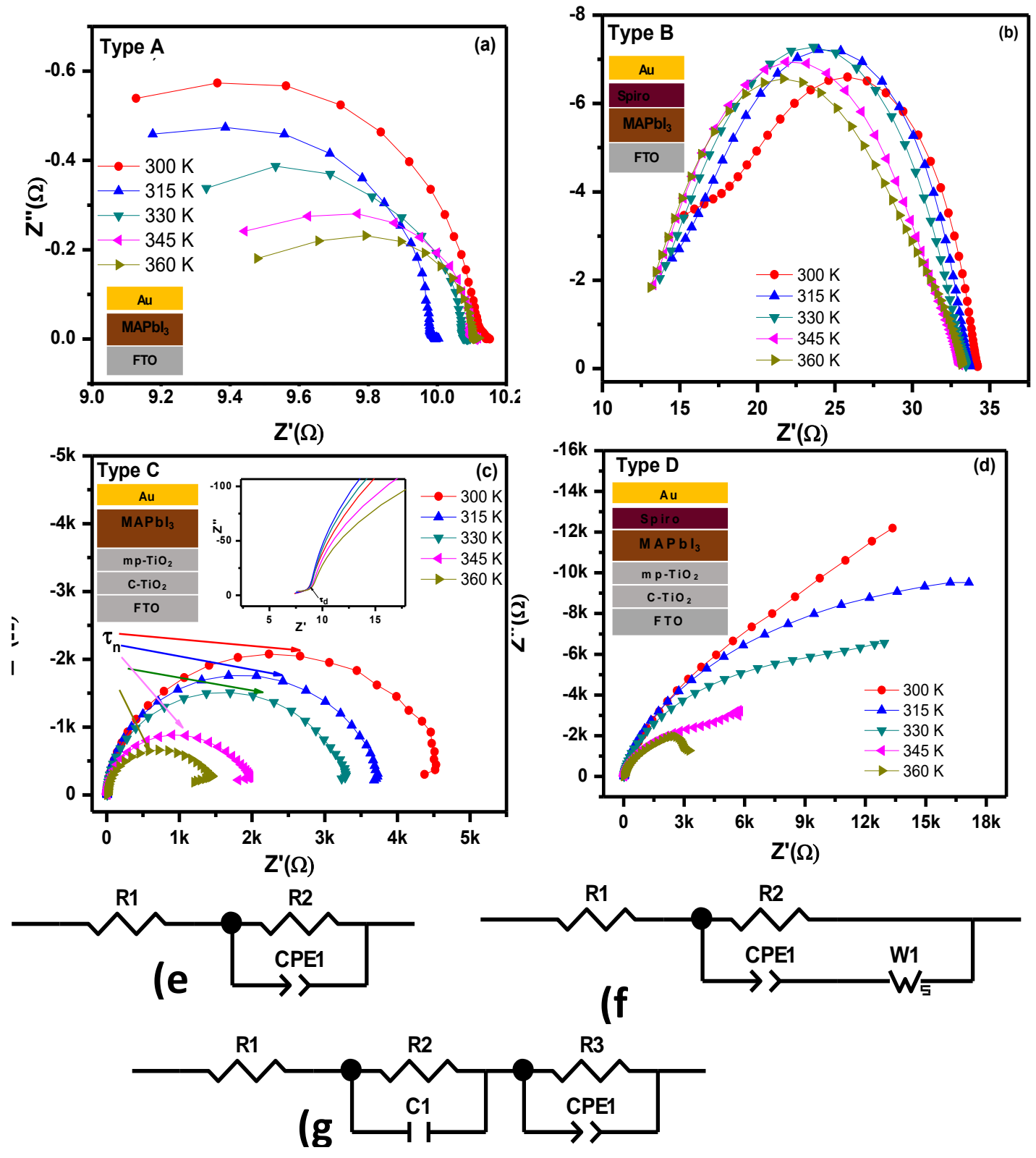

Figure 2. Impedance spectroscopy (IS) at different temperatures for (a) Type A (b),Type B (c),type C (d) type D and equivalent circuit (e) of type A \& C, (f) type B and (f) type D. 

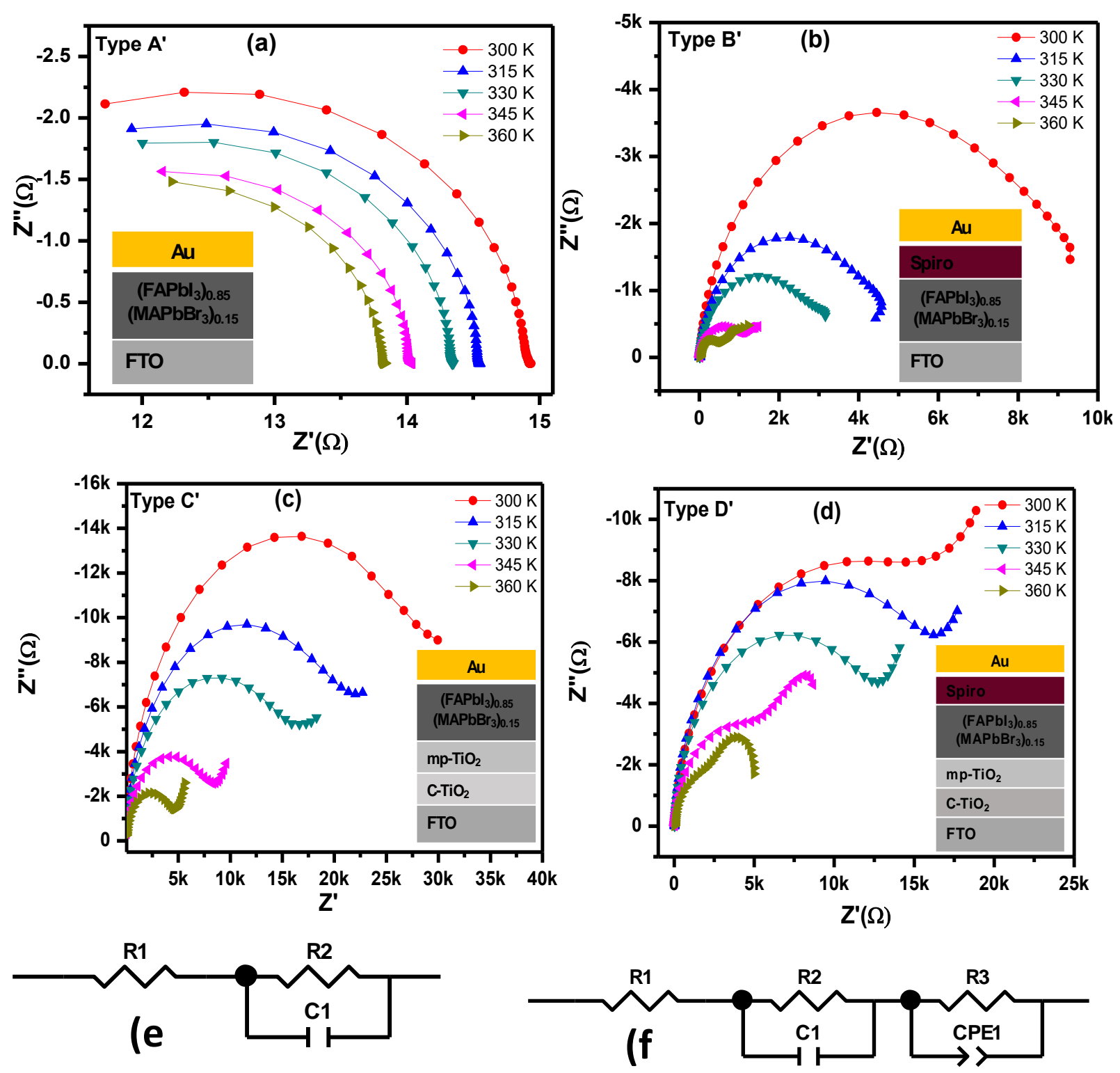

Figure 3. Impedance spectroscopy (IS) at different temperatures for (a) type $A^{\prime}$ (b) type $B^{\prime}$ (c) type $C^{\prime}(d)$ type $D^{\prime}$ and equivalent circuit (e) type $A^{\prime}$ (f) type $B^{\prime}-D^{\prime}$.

Moreover, higher interfacial and lower dielectric relaxation capacitance in $\left(\mathrm{FAPbI}_{3}\right)_{0.85}\left(\mathrm{MAPbBr}_{3}\right)_{0.15}$ are attributed to its higher charge accumulation at the interface and weak dielectric relaxation. Recombination time $\left(\tau_{\mathrm{n}}\right)$ deduced from peak position of IS (e.g. Figure 2c) are presented in Table 2 and Table 3. Additionally, the full devices showed higher recombination time as compared to unfinished devices. This suggest that charge SC, specifically, ESC, play a vital role in reducing the recombination current. The temperature dependence of recombination resistance $R_{r e c}$ (Figure 4) obtained from the fitting of above equivalent circuit, 
shows that the recombination resistance of all devices decreases with temperature due to increase in carriers concentration at higher temperature. Moreover, the devices with mixed perovskite showed higher value of $R_{\text {rec }}$ in all configuration, supports reduced recombination in $\left(\mathrm{FAPbI}_{3}\right)_{0.85}\left(\mathrm{MAPbBr}_{3}\right)_{0.15}$ as compared to $\mathrm{MAPbI}_{3}$. Additionally, the highest $R_{\text {rec }}$ value was deduced for devices with only ESC, therefore $\mathrm{TiO}_{2}$ play a major role in reducing the recombination current in perovskite solar cells.
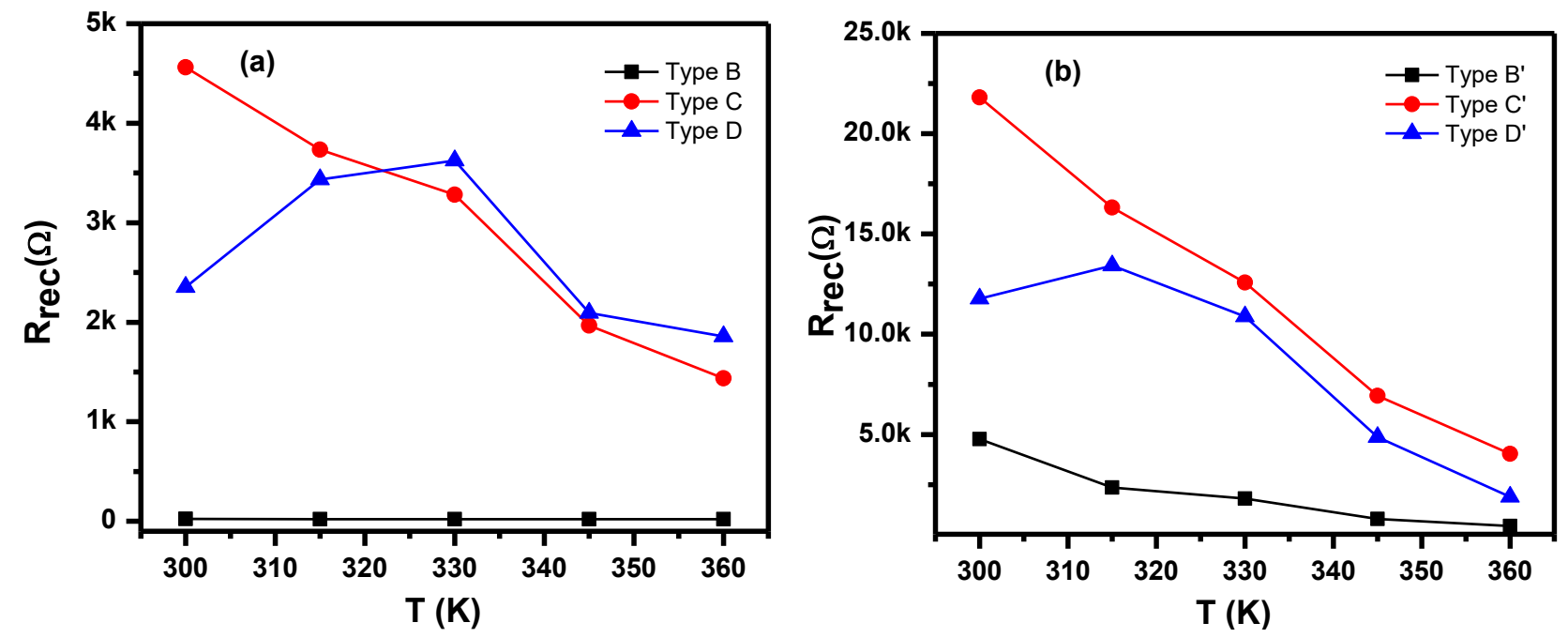

Figure 4. Recombination resistance as a function of temperature for (a) $\mathrm{MAPbI}_{3}$ and (b) $\left(\mathrm{FAPbI}_{3}\right)_{0.85}\left(\mathrm{MAPbBr}_{3}\right)_{0.15}$.

By the analysis of IS we have also derived the diffusion mobility $\mu$ of charge carriers in perovskite layer through the relation: $\mu=e D / k_{B} T$, where $k_{B}$ is the Boltzmann constant, $T$ is absolute temperature, $e$ is electronic charge and $D$ is the chemical diffusion coefficient. ${ }^{31-33}$ The electron diffusion coefficient was evaluated from the equation: $D=L^{2} / \tau_{d}$, where $L$ is thickness of perovskite layer and $\tau_{d}$ is carrier transit time. ${ }^{34}$ Transits time was calculated from IS as shown in Figure 2c. The diffusion time differ with device configuration and the type of perovskite used (Table 2 and 3). The devices with $\mathrm{MAPbI}_{3}$ gave a diffusion time in the order of $10^{-5}$ to $10^{-7} \mathrm{~s}$ while devices with $\left(\mathrm{FAPbI}_{3}\right)_{0.85}\left(\mathrm{MAPbBr}_{3}\right)_{0.15}$ yielded slightly lower diffusion time in the range of $10^{-6}$ to $10^{-8} \mathrm{~s}$. The calculated mobility are shown in Figure 5 and the devices with $\left(\mathrm{FAPbI}_{3}\right)_{0.85}\left(\mathrm{MAPbBr}_{3}\right)_{0.15}$ shows nearly two order of higher carrier mobility as compared to 
$\mathrm{MAPbI}_{3}$ devices. Higher mobility in $\left(\mathrm{FAPbI}_{3}\right)_{0.85}\left(\mathrm{MAPbBr}_{3}\right)_{0.15}$ is due to the reduced recombination current. The devices fabricated with hole SC (Type B \& B') showed lowest mobility while highest mobility was found for the devices with ESC. The specific value of mobility are tabled in Table 2 and 3. The mobility of Type D' is lower than of Type C' due to improved carrier recombination (Figure $4 \mathrm{~b}$ and Table 2). The devices fabricated with HSC gave lowest carrier mobility, arguably due to low carrier mobility of Spiro-OMeTAD $\left(10^{-5} \mathrm{~cm}^{2} / \mathrm{V} . \mathrm{s}\right)$ which impedes the charge diffusion through it. Other plausible reason for low carrier mobility of devices with HSC can be imbalance cations $\mathrm{MA}^{+}$and anions $\mathrm{I}^{-}$mobility in devices. ${ }^{42}$ Generally the diffusion coefficient of $\mathrm{I}^{-}$is about an order lower than that of $\mathrm{MA}^{+}$which allows slow cation migration and thus lower mobility. ${ }^{41}$

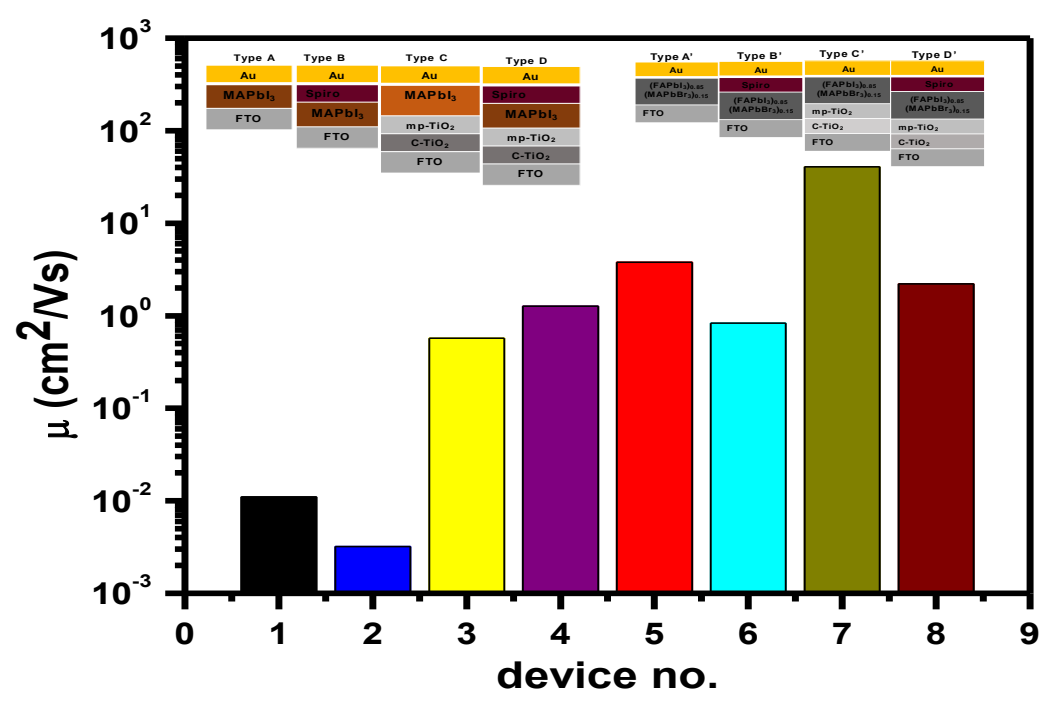

Figure 5. Charge carrier mobility in perovskite at $300 \mathrm{~K}$ in different device configurations.

Figure 6 displays the variation of capacitance (C) and conductance $(\mathrm{G})$ as a function of frequency at different temperatures. The $C-f$ graph shows three distinct regions at: low frequency (LF), intermediate frequency (IF) and high frequency (HF). In LF region $(20 \mathrm{~Hz}-1 \mathrm{kHz})$ capacitance decreases with frequency and is temperature dependent. In the IF range $(1 \mathrm{kHz}-100 \mathrm{kHz})$ a stable plateau was noted and capacitance value was found to be independent of frequency, however it shifted to a lower value with an increase in temperature. The stable plateau in IF range corresponds to dielectric relaxation in the perovskites layer and determined by the geometrical capacitance per unit area $C_{g}=\varepsilon \varepsilon_{0} / L$, where $\varepsilon$ is dielectric constant of perovskite, $\varepsilon_{0}$ is the vacuum permittivity and $L$ is the layer thickness. ${ }^{35}$ With an increase in temperature the geometrical capacitance of selective contact free devices decreases while the devices with selective contact show constant 
geometrical capacitance (Figure S8). With an increase in temperature, the geometrical capacitance of devices without selective contact (Type A \& A') decreases suggesting higher degree of charge recombination in light absorbing layer (perovskite). Moreover, the ions residing at the interface acquires sufficient thermal energy to leave the interface and migrate towards the bulk (Figure 7a) and acquire lower capacitance value. The devices without selective contact (Type A \& A') gave lowest capacitance as compared to other devices, pointing towards low degree of charge accumulation at interface as most of the charge carriers recombined in this case. While in the case of $\mathrm{HF}$ region $(100 \mathrm{kHz}-2 \mathrm{MHz})$, capacitance decreases with frequency. The drop in capacitance at HF corresponds to the effect of the series resistance caused by electrode contact. In LF region, the capacitance drops rapidly with frequency as compared to $\mathrm{TiO}_{2}$-free devices (type $\mathrm{A}, \mathrm{B} \&$ type A', B'). The drop of LF capacitance is ascribed to the polarization of interfaces owing to charge accumulation at the $\mathrm{TiO}_{2} /$ perovskite and perovskite/Spiro-OMeTAD interfaces. ${ }^{36-39}$ The devices fabricated with mixed perovskite showed similar trend, suggesting low frequency behavior is related to interfacial properties rather than bulk. The devices with electron selective contact (Type $\left.C \& C^{\prime}\right)$ reveal pronounced decrease in LF capacitance while the capacitance of devices with Spiro-OMeTAD (Type B, \& type B') decreases slowly. Low carrier mobility of $\mathrm{TiO}_{2}$ and energy level mismatch in $\mathrm{TiO}_{2} /$ perovskites can also led to charge accumulation at the $\mathrm{TiO}_{2} /$ perovskite interface. ${ }^{40}$ Another plausible reason for charge accumulation at $\mathrm{TiO}_{2} /$ perovskite interface might be weak interactions between $\mathrm{Ti}-\mathrm{I}$ which easily accommodate the charge carriers at the interface. ${ }^{41}$ The devices fabricated with $\left(\mathrm{FAPbI}_{3}\right)_{0.85}\left(\mathrm{MAPbBr}_{3}\right)_{0.15}$ gave slightly lower capacitance pointing towards the decrease of dielectric relaxation process in these devices leading to better charge transfer and improvement in carrier mobility. 

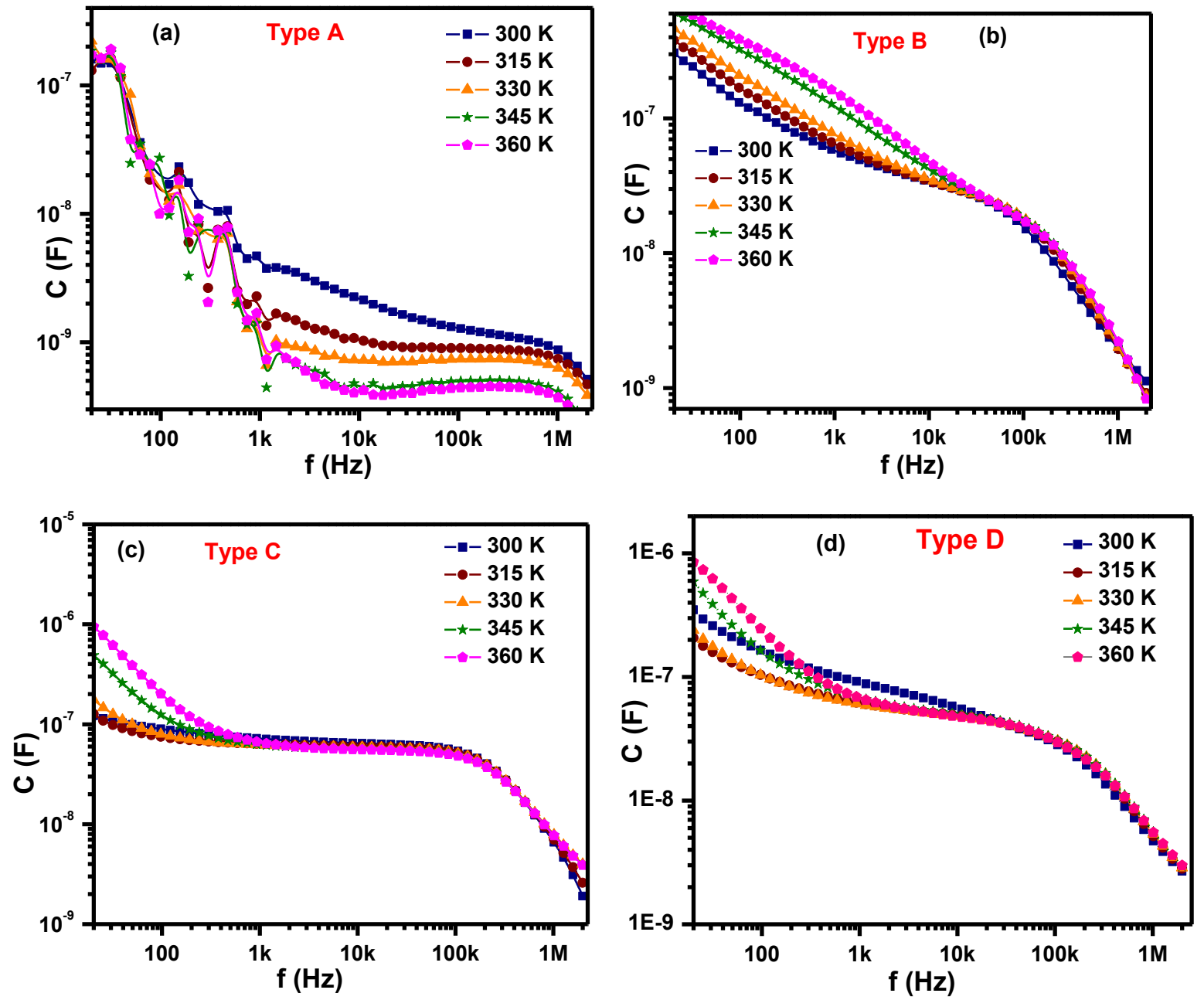

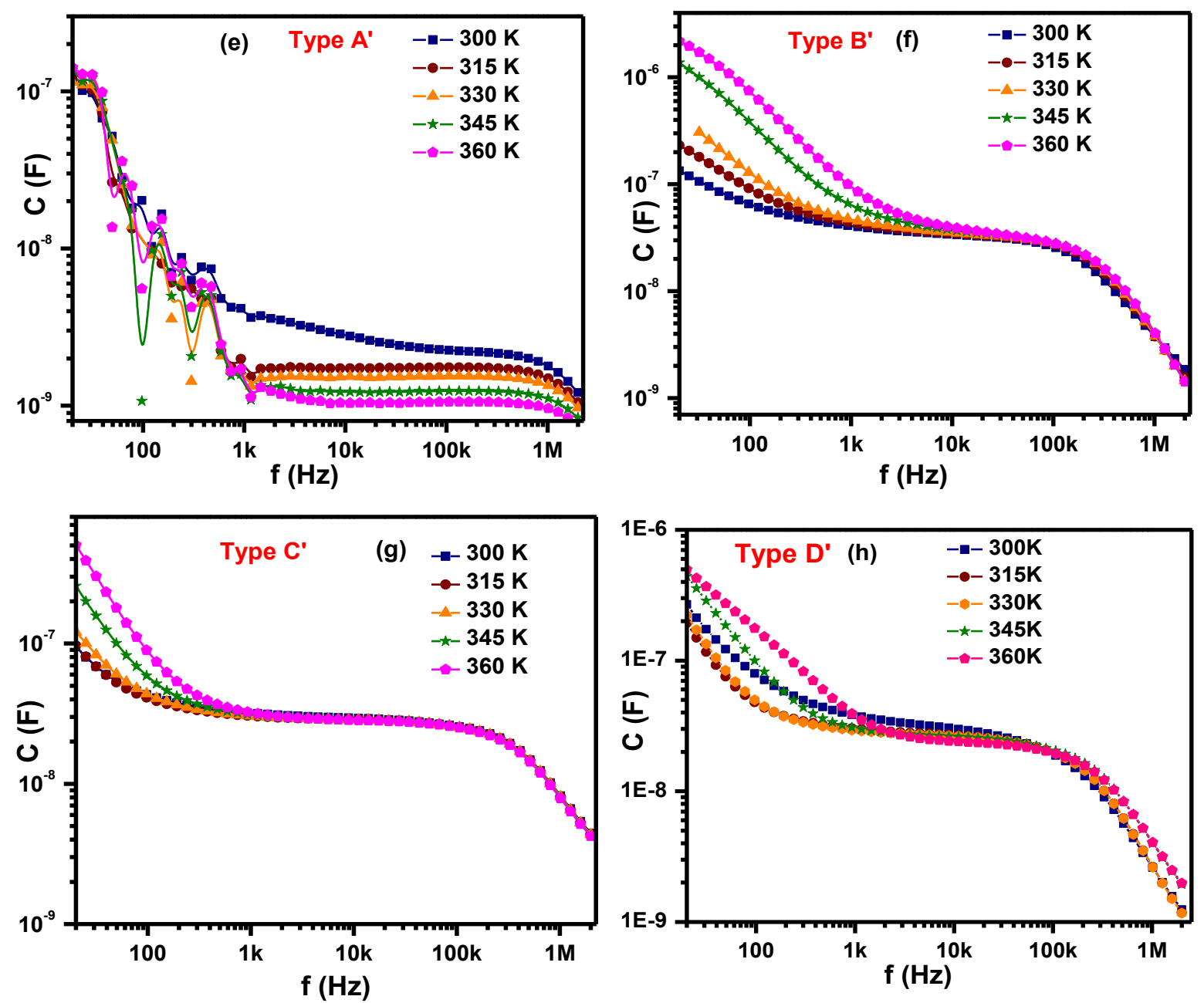

Figure 6. Capacitance as a function of frequency at different temperatures for (a) type A (b)type B (c) type C (d) type D (e) type A' (f) type B' (g) type C' (h) type D'.

Figure 7 shows the temperature dependence low frequency $(\sim 62 \mathrm{~Hz})$ capacitance of $\mathrm{MAPbI}_{3}$ and $\left(\mathrm{FAPbI}_{3}\right)_{0.85}\left(\mathrm{MAPbBr}_{3}\right)_{0.15}$ based devices. It can be noted (Figure 7), that the devices with HSC (type B \& B') gave highest interfacial capacitance while the devices without any selective contact (type A \& A') yielded lowest capacitance. These results suggest higher charge accumulation at perovskite/Spiro-OMeTAD interfaces as compared to $\mathrm{TiO}_{2} /$ perovskite interface (Figure 8). The higher charge accumulation at perovskite/Spiro-OMeTAD interface is due to (i) higher concentration of $\mathrm{MA}^{+}$as compared to $\mathrm{I}^{-}$and (ii) the diffusion coefficient of $\mathrm{MA}^{+}$is smaller than of $\mathrm{I}^{-42,43}$ Moreover, the hole selective layer Spiro-OMeTAD possesses low charge mobility. Due to unbalance charge extraction and transport this will allow capacitance to build-up at perovskite/HSC. Without any selective contacts, no such electrical interface can be formed and subsequently no losses at interface. In this case the capacitance will be mainly in the bulk of 
perovskites, while interfacial capacitance is not significant. Additionally, it can be noted (Figure 7) that the capacitance first decreases with increase in temperature until $315 \mathrm{~K}$, thereafter the capacitance of devices start increasing further with temperature. Such kind of capacitance behavior indicates ferroelectric-to-paraelectric transition, which originates due to phase transition of perovskites from tetragonal to cubic structure in the temperature range $315-330 \mathrm{~K} .{ }^{44}$ It is worthy to note that devices without selective contact shows on par behavior as of devices with selective contact. These findings reveal that the low frequency response is not only limited to interface charge accumulation but also related to the ferroelectric effect or an ion movement inside perovskite layer. ${ }^{45-47}$ Moreover, Figure S8 imply that the intermediate and high frequency signals shows less variation with temperature as of low frequency signal. Suggesting that the high frequency response are attributed to electronic process whereas the low frequency response are due to interfacial charge accumulation and ionic migration near the interface. ${ }^{47}$
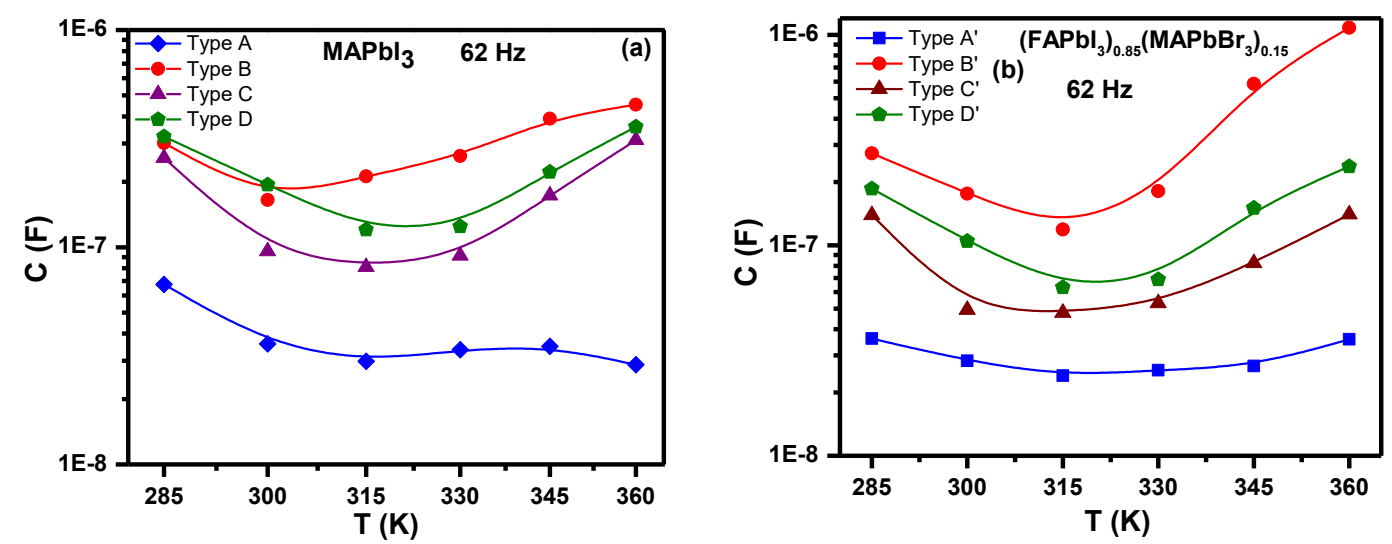

Figure 7. Temperature dependence of low frequency capacitance of a) $\mathrm{MAPbI}_{3}$ and b) mixed $\left(\mathrm{FAPbI}_{3}\right)_{0.85}\left(\mathrm{MAPbBr}_{3}\right)_{0.15}$ perovskite based devices.

To analyze the distribution of density of state (DOS) within the bandgap of the perovskites, the emission rate of electrons from the trap states and traps activation energy ${ }^{48,49}$ Capacitance vs. frequency (C-f) measurements at different temperatures was undertaken. In this process, with the decrease in frequency, deeper traps participate in capacitance, and thus increase in capacitance can be noted. 

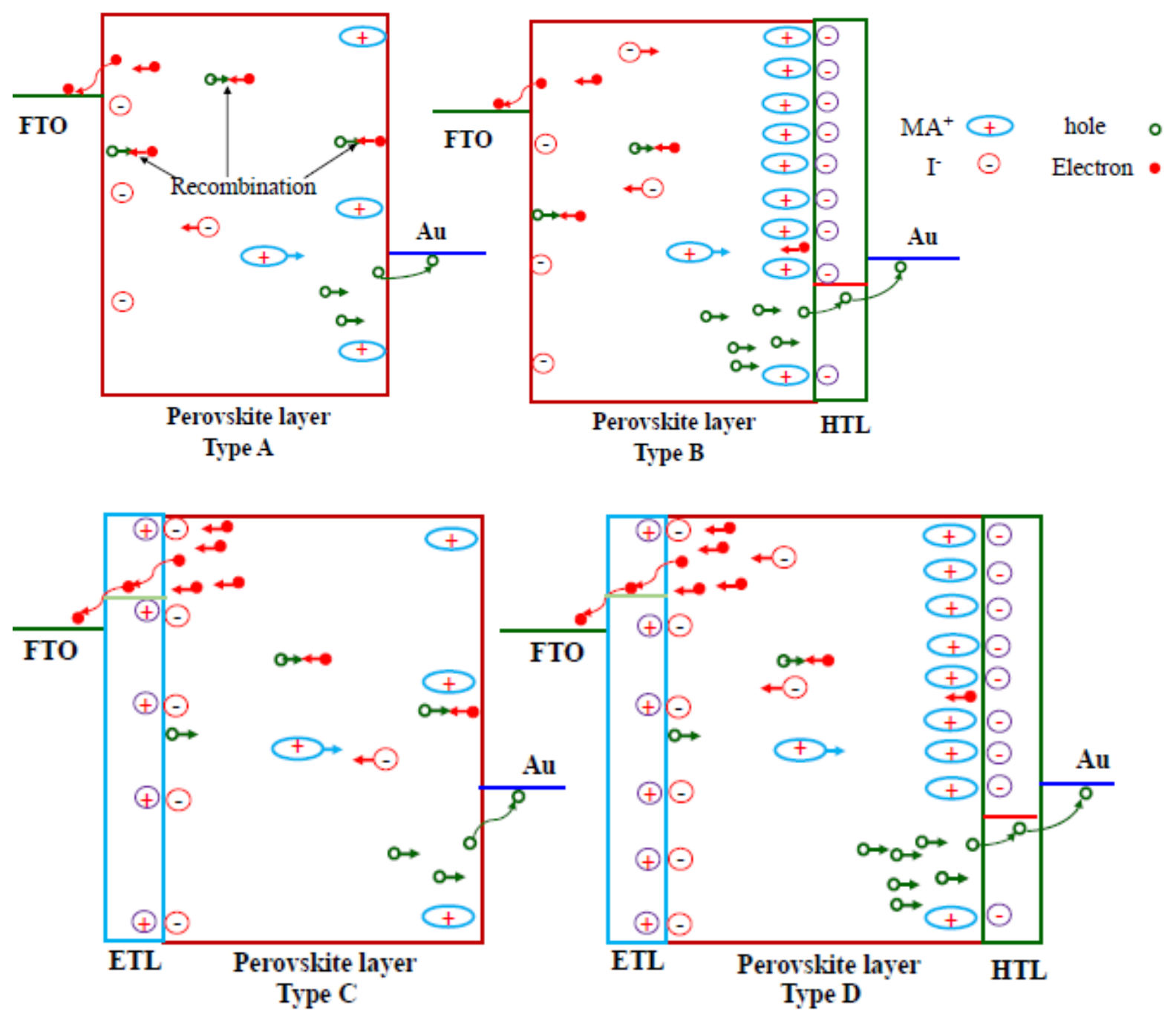

Figure 8. Schematic to depict the charge recombination and accumulation at ETL/perovskite and perovskite/HTL interface.

The emission rate of a charge carrier from a trap state at a given frequency strongly depends upon the energy of the trap and the temperature of device. The emission rate of electrons from a trap state located below $E_{T}$ to the conduction band edge $E_{C}$ is given by the relation: ${ }^{50-52}$

$$
e_{n}=N_{C} v_{t h} \sigma_{n} \exp \left(-\frac{E_{C}-E_{T}}{k_{B} T}\right)
$$

where $N_{C}$ is the effective density of states in the conduction band, $v_{t h}$ is the root mean square thermal velocity of electrons, $\sigma_{\mathrm{n}}$ is the capture cross section of trap and the product $N_{c} v_{t h} \sigma_{n}$ is 
called the attempt to escape frequency (ATEF) denoted by $v_{0}$. Since $N_{C} \propto T^{3 / 2}$ and rms speed $v_{t h} \propto T^{1 / 2}$, consequently, ATEF $v_{0} \propto T^{2}$, then equation 1 can be transformed to

$$
\ln \left(\frac{e_{n}}{T^{2}}\right)=\ln \xi-\frac{E_{A}}{k_{B} T}
$$

where $\xi$ is the proportionality constant and $E_{A}=E_{C}-E_{T}$ is the activation energy of the traps.

From the slope of Arrhenius plot, $\ln \left(\frac{f_{\text {peak }}}{T^{2}}\right) v s . \frac{1}{T} \quad$ (Figure S9) the value of activation energy can be deduced and the intercept of the line provide the value of ATEF. Where $f_{\text {peak }}$ is peak frequency extracted from [-f dC/df] vs. frequency plot shown in Figure 9. The calculated activation energy for devices are presented in Table 2 and 3. The activation energy is $\sim 55.57 \mathrm{meV}$ for charge selective contact free devices that slightly decreases for the devices with selective contact. The ATEF is $1.81 \times 10^{9} \mathrm{~Hz}$ for selective contact free devices and increase to $3.55 \times 10^{9} \mathrm{~Hz}\left(\mathrm{MAPbI}_{3}\right)$ and $2.35 \times 10^{9} \mathrm{~Hz}$ (Mixed perovskite) for the devices with SC and are in the customary range for organolead perovskites ${ }^{49}$. 

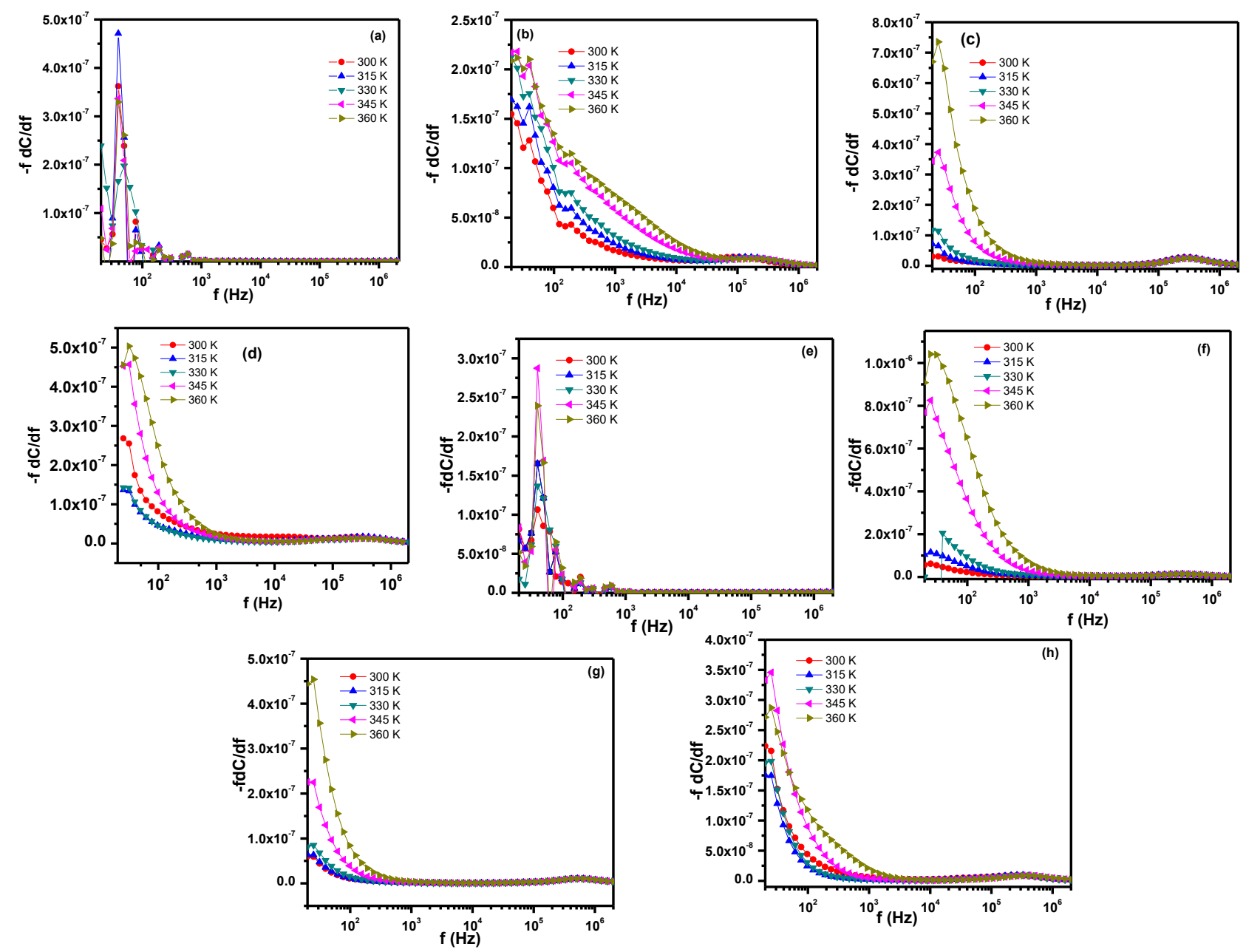

Figure 9. $\mathrm{f} \times \mathrm{dC} / \mathrm{df}$ vs. frequency at different temperatures for (a) Type A, (b) Type B, (c) Type C, (d) Type D, (e) Type A', (f) Type B', (g) Type C', (h) Type D'.

Figure 9 show the experimental data for [-f dC/df] vs. frequency, measured at various temperatures for $\mathrm{MAPbI}_{3}$ and $\left(\mathrm{FAPbI}_{3}\right)_{0.85}\left(\mathrm{MAPbBr}_{3}\right)_{0.15}$. There is a secondary peak related to a deeper trap in addition to the shallow traps near the edge of conduction band. The density of states $\left(N_{C}\right)$ at the edge of conduction band (shallow traps) deduced from these plots is $\sim 2.70 \times 10^{14} \mathrm{~cm}^{-3}$ for selective contact free devices and the value increases for devices with selective contact. The device fabricated from $\mathrm{MAPbI}_{3}$ have slightly higher density of state of $\mathrm{N}_{\mathrm{C}} \sim 4.62 \times 10^{14} \mathrm{~cm}^{-3}$ as compared to the $\left(\mathrm{FAPbI}_{3}\right)_{0.85}\left(\mathrm{MAPbBr}_{3}\right)_{0.15}$ of $\sim 1.82 \times 10^{14} \mathrm{~cm}^{-3}$.

The density distribution of trap states was evaluated by using Mott-Schottky analysis and admittance spectroscopy. The distribution of trap state density can be derived from the equation: ${ }^{.8}$ 


$$
\begin{array}{r}
N_{T}=-\frac{V_{b i}}{q W k_{B} T}\left(f \frac{d C}{d f}\right) \\
E_{\omega}=k_{B} T \ln \left(\frac{\omega_{0}}{\omega}\right)
\end{array}
$$

where $\mathrm{V}_{\mathrm{bi}}$ is the built-in potential, $\mathrm{W}$ is the depletion width, $\mathrm{q}$ is the elementary charge, and $\omega$ is the applied angular frequency. A Mott-Schottky plot: $\frac{1}{C^{2}}=\frac{2\left(V_{b i}-V\right)}{A q \varepsilon \varepsilon_{0} N}$ of device D and D' measured at $10 \mathrm{kHz}$ is shown in Figure 10 (a). The slope of straight line gives the impurity doping density $\mathrm{N}$ and intersection on the voltage axis determines $\mathrm{V}_{\mathrm{bi}}$. The depletion width corresponds to the zero bias was calculated by equation:

$$
W=\sqrt{\frac{\varepsilon \varepsilon_{0} V_{b i}}{q N}}
$$

and found to be $206 \mathrm{~nm}$ and $261 \mathrm{~nm}$ for device D and D', respectively. The built in potential for device type D and D' was found to be $0.69 \mathrm{~V}$ and $1.05 \mathrm{~V}$ respectively. From these results, the density distribution and energy levels of trap states at $300 \mathrm{~K}$ in these devices are displayed in Fig. 10b. It can be observed from Figure that the peak value of traps in device D and D' are located at $0.42 \mathrm{eV}$ and $0.70 \mathrm{eV}$ with peak value of $1.37 \times 10^{17}\left(\mathrm{eV} \mathrm{cm}^{3}\right)^{-1}$ and $8.84 \times 10^{16}\left(\mathrm{eV} \mathrm{cm}^{3}\right)^{-1}$, respectively. 

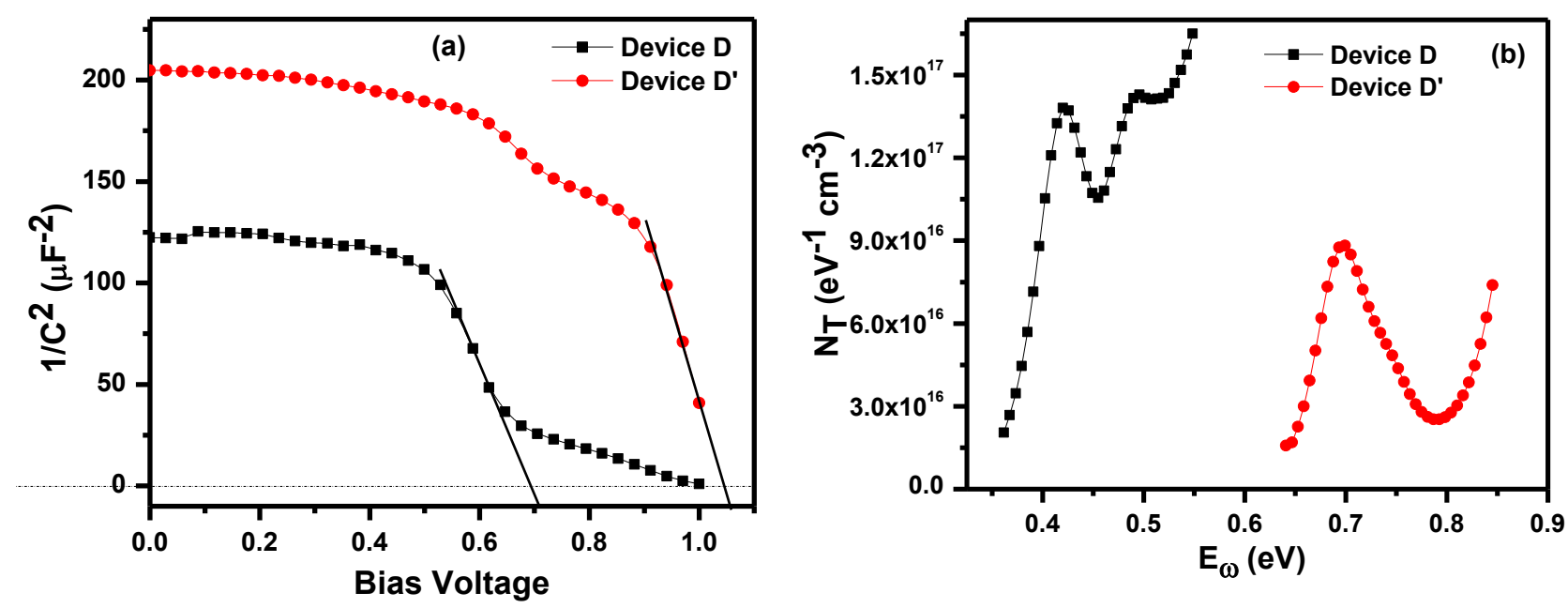

Figure 10. (a) Mott-Schottky analysis of device D and D' at $10 \mathrm{kHz}$, (b) trap state density $\left(\mathrm{N}_{\mathrm{T}}\right)$ of device D and D' measured at $300 \mathrm{~K}$.

Table 2. Electrical parameters calculated for $\mathrm{MAPbI}_{3}$ perovskite at $300 \mathrm{~K}$.

\begin{tabular}{lllll}
\hline Parameters/devices & Type A & Type B & Type C & Type D \\
\hline$\mu\left(\mathrm{cm}^{2} / \mathrm{V} . \mathrm{s}\right)$ & $1.1 \times 10^{-2}$ & $3.19 \times 10^{-3}$ & $5.7 \times 10^{-1}$ & 1.27 \\
\hline Diffusion time $\tau_{\mathrm{d}}(\mu \mathrm{s})$ & 14.3 & 55.45 & 1.57 & 0.308 \\
\hline Recombination time $\tau_{\mathrm{n}}(\mu \mathrm{s})$ & 0.100 & 1.88 & 338 & 6366 \\
\hline Activation energy $\mathrm{E}_{\mathrm{A}}(\mathrm{meV})$ & 55.57 & 55.57 & 55.57 & 82.96 \\
\hline ATEF $\nu_{0}(\mathrm{~Hz})$ & $1.77 \times 10^{9}$ & $3.48 \times 10^{9}$ & $3.48 \times 10^{9}$ & $5.40 \times 10^{12}$ \\
\hline
\end{tabular}

Table 3. Electrical parameters calculated for mixed perovskite at $300 \mathrm{~K}$.

\begin{tabular}{lllll}
\hline Parameters/devices & Type A' & Type B' & Type C' & Type D' \\
\hline$\mu\left(\mathrm{cm}^{2} / \mathrm{V} . \mathrm{s}\right)$ & 3.78 & 0.83 & 40.55 & 2.21 \\
\hline Diffusion time $\tau_{\mathrm{d}}(\mathrm{ns})$ & 540 & 2460 & 196 & 386 \\
\hline Recombination time $\tau_{\mathrm{n}}(\mu \mathrm{s})$ & 0.100 & 423 & 1320 & 1300 \\
\hline Activation energy $\mathrm{E}_{\mathrm{A}}(\mathrm{meV})$ & 55.57 & 50.54 & 50.54 & 124 \\
\hline ATEF $v_{0}(\mathrm{~Hz})$ & $1.77 \times 10^{9}$ & $2.30 \times 10^{9}$ & $2.30 \times 10^{9}$ & $2.13 \times 10^{17}$ \\
\hline
\end{tabular}

\section{Conclusions}

Herein, we have investigated the role of electron and hole selective contact (SC) in perovskite solar cells by means of impedance spectroscopy. The devices fabricated with $\left(\mathrm{FAPbI}_{3}\right)_{0.85}\left(\mathrm{MAPbBr}_{3}\right)_{0.15}$ shows higher charge accumulation at perovskite/SC interface as compared to $\mathrm{MAPbI}_{3}$ based one. Moreover, we have also noted that charge accumulation at hole selective interface is higher as compared to electron selective interface. The devices fabricated with both (electron and hole) SC 
shows low level of recombination as compare to the devices without any SC that shows high degree of recombination. $\left(\mathrm{FAPbI}_{3}\right)_{0.85}\left(\mathrm{MAPbBr}_{3}\right)_{0.15}$ based devices gave reduced recombination and high carrier mobility. The maximum mobility for $\mathrm{MAPbI}_{3}$ and $\left(\mathrm{FAPbI}_{3}\right)_{0.85}\left(\mathrm{MAPbBr}_{3}\right)_{0.15}$ was found to be 1.27 and $40.55 \mathrm{~cm}^{2} / \mathrm{Vs}$ at room temperature $(300 \mathrm{~K})$, respectively in our experimental setup. In order to elucidate the DOS and trap states in the band gap of perovskites, temperature dependent C-f experiments were used. The activation energy for both perovskite was found to be $55.57 \mathrm{meV}$ for SC-free devices, however this parameter increases and represent a value of $123 \mathrm{meV}$ (for mixed perovskite) and $82.96 \mathrm{meV}$ (for $\mathrm{MAPbI}_{3}$ ) for devices fabricated with both electron and hole SC. The peak value of traps in $\mathrm{MAPbI}_{3}$ and mixed perovskite devices are located at $0.42 \mathrm{eV}$ and 0.70 $\mathrm{eV}$ with peak value of $1.37 \times 10^{17}$ and $8.84 \times 10^{16} \mathrm{eV}^{-1} \mathrm{~cm}^{-3}$, respectively.

\section{Experimental part}

\section{Device fabrication details}

FTO-coated glass (TEC15, Pilkington) patterned by laser etching was employed for the fabrication of perovskite based solar cells. Substrates were cleaned by ultrasonication in three different solutions with the aim to eliminate any possible contamination. First a Hellmanex ${ }^{\circledR}$ solution (2\%) were used and rinsed with deionized water and ethanol. Then samples were ultrasonicated for 30 minutes in acetone, and 2-propanol and finally they were dried by using nitrogen. After this step, a $\mathrm{TiO}_{2}$ compact layer was deposited by spray pyrolysis at $450{ }^{\circ} \mathrm{C}$ using titanium (IV) diisopropoxide bis(acetyl acetonate) precursor solution (1/19 v/v ratio in ethanol, Sigma Aldrich) using oxygen as a carrier gas. The $\mathrm{TiO}_{2}$ blocking layer was then kept for 30 minutes at $450{ }^{\circ} \mathrm{C}$ for the formation of anatase phase. After the samples attained room temperature, the $\mathrm{ESC}$ i.e $\mathrm{TiO}_{2}$ mesoporous layer (Dyesol, 30NRD) was deposited by spin coating (4,000 rpm for $20 \mathrm{~s}$ ) and annealed at $500{ }^{\circ} \mathrm{C}$ using ramp heating process. Subsequently, pure methyl ammonium $\left(\mathrm{MAPbI}_{3}\right)$ or mixed cation perovskite $\left(\left(\mathrm{FAPbI}_{3}\right)_{0.85}\left(\mathrm{MAPbBr}_{3}\right)_{0.15}\right)$ was then deposited according to our previous reports ${ }^{12,39}$. All solutions were prepared inside an argon glove box under controlled moisture and oxygen conditions $\left(\mathrm{H}_{2} \mathrm{O}\right.$ level: <1 ppm and $\mathrm{O}_{2}$ level: <10 ppm). Optimized concentrations were prepared depending on the perovskite fabricate (1.2M and $1.4 \mathrm{M})$ respectively. The perovskite solution was spin coated in a two steps setup at 1000 and $5000 \mathrm{rpm}$ for 10 and 20s respectively. During the second step, $110 \mu \mathrm{L}$ of chlorobenzene was dropped on the spinning substrate 15 seconds before the end of the spinning program as an anti-solvent approach. The 
samples were then annealed $\left(100^{\circ} \mathrm{C}\right)$ for $1 \mathrm{~h}$ in an argon filled glove box. After perovskite deposition, annealing and cool down, $35 \mu \mathrm{L}$ of a Spiro-OMeTAD solution was then spin coated at $4000 \mathrm{rpm}$ for 20 seconds as hole transporting material. Spiro-OMeTAD material $(70 \mathrm{mM})$ were dissolved in $1 \mathrm{~mL}$ of chlorobenzene using standard additives as $17.5 \mu \mathrm{L}$ of a lithium bis(trifluoromethylsulphonyl)imide (LiTFSI) stock solution (520 mg of LiTFSI in $1 \mathrm{~mL}$ of acetonitrile), $21.9 \mu \mathrm{L}$ of a FK209 (Tris(2-(1H-pyrazol-1-yl)-4-tertbutylpyridine) cobalt(III)Tris(bis(trifluoromethylsulfonyl)imide))) stock solution (400 $\mathrm{mg}$ in $1 \mathrm{~mL}$ of acetonitrile) and $28.8 \mu \mathrm{L}$ of 4-tert-butylpyridine ( $t$-BP). For all devices, $80 \mathrm{~nm}$ of gold was deposited by thermal evaporation under a vacuum level between $1 \times 10^{-6}$ and $1 \times 10^{-5}$ torr.

\section{Device characterization}

Cross-sectional and top-view microstructure were recorded by a Hitachi S-4800 scanning electron microscope and used for thickness evaluation. Impedance measurements at different temperatures were performed on a Keysight precision LCR meter model No. E4980A. Samples were measured at different temperatures $(300-360 \mathrm{~K})$ using a Linkam sample chamber heating stage filled with nitrogen in a closed environment, to control the degradation of the samples for humidity conditions. After measurement, data were fitted by Z-view (version 3.1c) software in order to extract characteristic parameters of the cells.

\section{Conflicts of interest}

The authors declare no conflict of interest.

\section{Acknowledgements}

This work has received funding from the European Union Seventh H2020 Programme under European Research council Consolidator grant [MOLEMAT, 726360]

\section{References}

1 N. J. Jeon, J. H. Noh, W. S. Yang, Y. C. Kim, S. Ryu, J. Seo, S. Il Seok, Nature 2015, 517, 470-480.

2 M. Saliba, T. Matsui, J. Y. Seo, K. Domanski, J. P. Correa-Baena, M. K. Nazeeruddin, S. M. Zakeeruddin, W. Tress, A. Abate, A. Hagfeldt, M. Grätzel, Energy Environ. Sci. 2016, 
9, 1989-1997; S. Kazim, M.^^K. Nazeeruddin, M. Grätzel, S. Ahmad, Angew. Chem. Int.

Ed. 2014, 53, 2812--2824; Angew. Chem. 2014, 126, 2854--2867</jnl>.

3 NREL Efficiency Chart. http://www.nrel.gov/ncpv/images/ efficiency_chart.jpg.

4 Q. Zhang, R. Su, W. Du, X. Liu, L. Zhao, S. T. Ha, Q. Xiong, Small Methods 2017, 1, 1700163.

5 T. Matsushima, C. Qin, K. Goushi, F. Bencheikh, T. Komino, M. Leyden, A. S. D. Sandanayaka, C. Adachi, Adv. Mater. 2018, 1802662 , DOI:10.1002/adma.201802662.

6 Z. Xiao, R. A. Kerner, L. Zhao, N. L. Tran, K. M. Lee, T. W. Koh, G. D. Scholes, B. P. Rand, Nat. Photonics 2017, 11, 108-115.

7 B. Chen, M. Yang, X. Zheng, C. Wu, W. Li, Y. Yan, J. Bisquert, G. Garcia-Belmonte, K. Zhu, S. Priya, J. Phys. Chem. Lett. 2015, 6, 4693-4700.

8 S. Van Reenen, M. Kemerink, H. J. Snaith, J. Phys. Chem. Lett. 2015, 6, 3808-3814.

9 H. Yu, H. Lu, F. Xie, S. Zhou and N. Zhao, Adv. Funct. Mater. 2016, 26, 1411-1419.

10 Y. Shao, Z. Xiao, C. Bi, Y. Yuan and J. Huang, Nat. Commun. 2014, 5:5784, DOI:10.1038/ncomms6784.

11 L. K. Ono, Y. Qi, S. (Frank) Liu, Joule 2018, 2, 1961-1990.

12 M. Salado, J. Idigoras, L. Calio, S. Kazim, M. K. Nazeeruddin, J. A. Anta, S. Ahmad, ACS Appl. Mater. Interfaces 2016, 50, 34414-34421.

13 Y. Yuan, J. Huang, Acc. Chem. Res. 2016, 49, 286-293.

14 Z. Li, C. Xiao, Y. Yang, S. P. Harvey, D. H. Kim, J. A. Christians, M. Yang, P. Schulz, S. U. Nanayakkara, C. S. Jiang, J. M. Luther, J. J. Berry, M. C. Beard, M. M. Al-Jassim and K. Zhu, Energy Environ. Sci. 2017, 10, 1234-1242.

15 S. Cacovich, L. Ciná, F. Matteocci, G. Divitini, P. A. Midgley, A. Di Carlo and C. Ducati, Nanoscale 2017, 9, 4700-4706.

16 L. Caliò, M. Salado, S. Kazim, S. Ahmad, Joule 2018, 2, 1800-1815.

17 E. J. Juarez-Perez, R. S. Sanchez, L. Badia, G. Garcia-Belmonte, Y. S. Kang, I. M. Sero, J. Bisquert, J. Phys. Chem. Lett. 2014, 5, 2390-2394.

18 H. Tsai, R. Asadpour, J.-C. Blancon, C. C. Stoumpos, O. Durand, J. W. Strzalka, B. Chen, R. Verduzco, P. M. Ajayan, S. Tretiak, J. Even, M. A. Alam, M. G. Kanatzidis, W. Nie, A. D. Mohite, Science 2018, 360, 67-70.

19 J. M. Frost, K. T. Butler, F. Brivio, C. H. Hendon, M. van Schilfgaarde, A. Walsh, Nano 
Lett. 2014, 14, 2584-90.

20 H. S. Duan, H. Zhou, Q. Chen, P. Sun, S. Luo, T. Bin Song, B. Bob, Y. Yang, Phys. Chem. Chem. Phys. 2015, 17, 112-116.

21 M. N. F. Hoque, M. Yang, Z. Li, N. Islam, X. Pan, K. Zhu, Z. Fan, ACS Energy Lett. 2016, $1,142-149$.

22 K. Wang, Y. Shi, Q. Dong, Y. Li, S. Wang, X. Yu, M. Wu, T. Ma, J. Phys. Chem. Lett. 2015, 6, 755-759.

23 J. F. Wang, L. Zhu, B. G. Zhao, Y. L. Zhao, J. Song, X. Q. Gu, Y. H. Qiang, Sci. Rep. 2017, 7,14478 .

24 A. Todinova, L. Contreras-Bernal, M. Salado, S. Ahmad, N. Morillo, J. Idígoras, J. A. Anta, ChemElectroChem 2017, 4, 2891-2901.

25 E. J. Juarez-Perez, M. Wußler, F. Fabregat-Santiago, K. Lakus-Wollny, E. Mankel, T. Mayer, W. Jaegermann, I. Mora-Sero, J. Phys. Chem. Lett. 2014, 5, 680-685.

26 V. Gonzalez-Pedro, E. J. Juarez-Perez, W. S. Arsyad, E. M. Barea, F. Fabregat-Santiago, I. Mora-Sero, J. Bisquert, Nano Lett. 2014, 14, 888-893.

27 A. Dualeh, T. Moehl, N. Tétreault, J. Teuscher, P. Gao, M. K. Nazeeruddin, M. Grätzel, ACS Nano, 2014, 8, 362-373.

28 H. S. Kim, I. Mora-Sero, V. Gonzalez-Pedro, F. Fabregat-Santiago, E. J. Juarez-Perez, N. G. Park, J. Bisquert, Nat. Commun. 2013, 4, 2242.

29 W. H. Mulder, J. H. Sluyters, T. Pajkossy, L. Nyikos, J. Electroanal. Chem. 1990, 285, $103-115$.

30 J. Vogelsang, W. Strunz, Electrochim. Acta 2001, 46, 3619-3625.

31 G. Garcia-Belmonte, J. Bisquert, G. S. Popkirov, Appl. Phys. Lett. 2003, 83, 2178-2180.

32 G. Garcia-Belmonte, A. Munar, E. M. Barea, J. Bisquert, I. Ugarte, R. Pacios, Org. Electron. physics, Mater. Appl. 2008, 9, 847-851.

33 J. Bisquert, Phys. Chem. Chem. Phys. 2008, 10, 3175-3194.

34 J. Bisquert, J. Phys. Chem. B 2002, 106, 325-333.

35 O. Almora, C. Aranda, G. Garcia-Belmonte, J. Phys. Chem. C 2018, 122, 13450-13454.

36 O. Almora, A. Guerrero, G. Garcia-Belmonte, Appl. Phys. Lett. 2016, 108, 043903.

37 S. Ravishankar, S. Gharibzadeh, C. Roldán-Carmona, G. Grancini, Y. Lee, M. Ralaiarisoa, A. M. Asiri, N. Koch, J. Bisquert, M. K. Nazeeruddin, Joule 2018, 2, 788-798. 
G. Garcia-Belmonte, J. Bisquert, ACS Energy Lett. 2016, 1, 683-688.

39 M. Salado, L. Calió, L. Contreras-Bernal, J. Idígoras, J. A. Anta, S. Ahmad, S. Kazim, Materials, 2018, 7, 1073.

40 I. Zarazua, J. Bisquert, G. Garcia-Belmonte, J. Phys. Chem. Lett. 2016, 7, 525-528.

41 V. Roiati, E. Mosconi, A. Listorti, S. Colella, G. Gigli, F. De Angelis, Nano Lett. 2014, 14, $2168-2174$.

42 M. H. Futscher, J. M. Lee, L. McGovern, L. A. Muscarella, T. Wang, M. Irfan Haider, A. Fakharuddin, L. S.-Mende, B. Ehrler, Mater. Horiz. 2019, DOI: 10.1039/c9mh00445a.

43 J. M. Azpiroz, E. Mosconi, J. Bisquert, F. De Angelis, Energy Environ. Sci. 2015, 8, 21182127.

44 Y. Rakita, O. Bar-Elli, E. Meirzadeh, H. Kaslasi, Y. Peleg, G. Hodes, I. Lubomirsky, D. Oron, D. Ehre, D. Cahen, Proc. Natl. Acad. Sci. 2017, 114, E5504-E5512.

45 L. Contreras, S. Ramos-Terrón, A. Riquelme, P. P. Boix, J. A. Idígoras, I. Mora Seró, J. A. Anta, J. Mater. Chem. 2019, 7, 12191-12200.

46 H. Zhang, X. Qiao, Y. Shen, T. Moehl, S. M. Zakeeruddin, M. Grätzel, M. Wang, J. Mater. Chem. A 2015, 3, 11762-11767.

47 Z. Xiao, Y. Yuan, Y. Shao, Q. Wang, Q. Dong, C. Bi, P. Sharma, A. Gruverman, J. Huang, Nat. Mater. 2015, 14, 193-197.

48 T. Walter, R. Herberholz, C. Müller, H. W. Schock, J. Appl. Phys. 1996, 80, 4411-4420.

49 M. Samiee, S. Konduri, B. Ganapathy, R. Kottokkaran, H. A. Abbas, A. Kitahara, P. Joshi, L. Zhang, M. Noack, V. Dalal, Appl. Phys. Lett. 2014, 105, 153502.

50 D. K. Schroder, Semiconductor Material and Device Characterization: Third Edition, 2005.

51 R. F. Pierret, G. W. Neudeck, Summary for Policymakers, 1987.

52 J. A. Carr, M. Elshobaki, S. Chaudhary, Appl. Phys. Lett. 2015, 107, 203302.

53. X. Dong, D. Chen, J. Zhou, Y.Z. Zheng, X. Tao, Nanoscale 2018, 10, 7218-7227.

54. J. Zhang, P. Barboux, T. Pauporté, Adv. Energy Mater 2014, 4, 1400932.

55. J. Zhang, E. José Juárez-Pérez, I. Mora-Seró, B. Viana, T. Pauporté, J. Mater. Chem. A 2015, 3, 4909-4915.

56. J. Zhang, T. Pauporté, J. Phys. Chem. C 2015, 119, 14919-14928.

57. H.-Seon Kim, J.-Wook Lee, N. Yantara, P. P. Boix, S. A. Kulkarni, S. Mhaisalkar, M. Grätzel, N.-Gyu Park, Nano Lett. 2013, 13, 2412-2417. 
58. N. Li et al., Nat. Energy, 2019, 4, 408-415. 


\section{SUPPORTING INFORMATION}

Elucidating the impact of charge selective contact in halide perovskite

through impedance spectroscopy

Mohd Taukeer Khan ${ }^{\mathrm{a}, \mathrm{c}}$, Manuel Salado ${ }^{a}$, Abdullah Almohammedi ${ }^{\mathrm{c}}$ Samrana Kazim, ${ }^{a, b}$ and Shahzada Ahmad, , $^{*}$

${ }^{a}$ BCMaterials-Basque Center for Materials, Applications and Nanostructures, Martina Casiano, UPV/EHU Science Park, Barrio Sarriena s/n, Leioa 48940, Spain.

${ }^{b}$ IKERBASQUE, Basque Foundation for Science, Bilbao, 48013, Spain.

${ }^{c}$ Department of Physics, Faculty of Science, Islamic University of Madinah, Prince Naifbin Abdulaziz, Al Jamiah, Madinah 42351, Kingdom of Saudi Arabia.

Tel: +34 946128811 Email: shahzada.ahmad@bcmaterials.net 


\section{S1. Fitting of Impedance spectra}

The fitting of impedance spectra and equivalent circuit are shown in following figures. In these figures the resistance $R_{1}, R_{2}$ and $R_{3}$ represents the contact resistance of wire and FTO, recombination resistance in perovskite layer and selective contacts resistance, respectively. The capacitance corresponds to $\mathrm{R}_{2}$ represents the dielectric relaxation in perovskite and other one represents the interfacial capacitances between the perovskite and charge selective contacts (ESC and HSC).

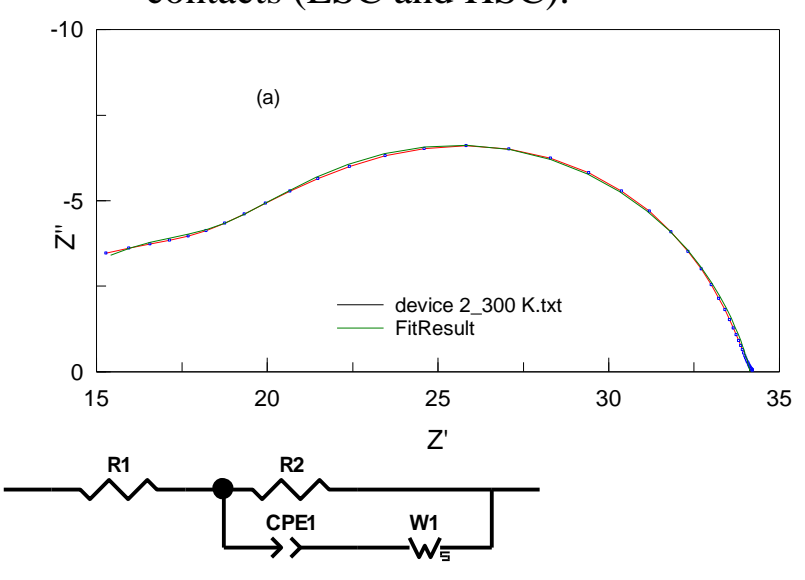

\begin{tabular}{|c|c|c|c|c|}
\hline Element & Freedom & $\underline{\text { Value }}$ & Error & Error \% \\
\hline $\mathrm{R} 1$ & Free(+) & 11.46 & 0.16058 & 1.4012 \\
\hline $\mathrm{R} 2$ & Free(+) & 22.68 & 0.15843 & 0.69854 \\
\hline CPE1-T & Free(+) & 4.7482E-07 & 2.2503E-08 & 4.7393 \\
\hline CPE1-P & Free(+) & 0.84468 & 0.0031308 & 0.37065 \\
\hline W1-R & Free(+) & 7.943 & 0.40316 & 5.0757 \\
\hline W1-T & Free(+) & $3.491 \mathrm{E}-07$ & 9.9859E-09 & 2.8605 \\
\hline W1-P & Free(+) & 0.46679 & 0.0099446 & 2.1304 \\
\hline
\end{tabular}
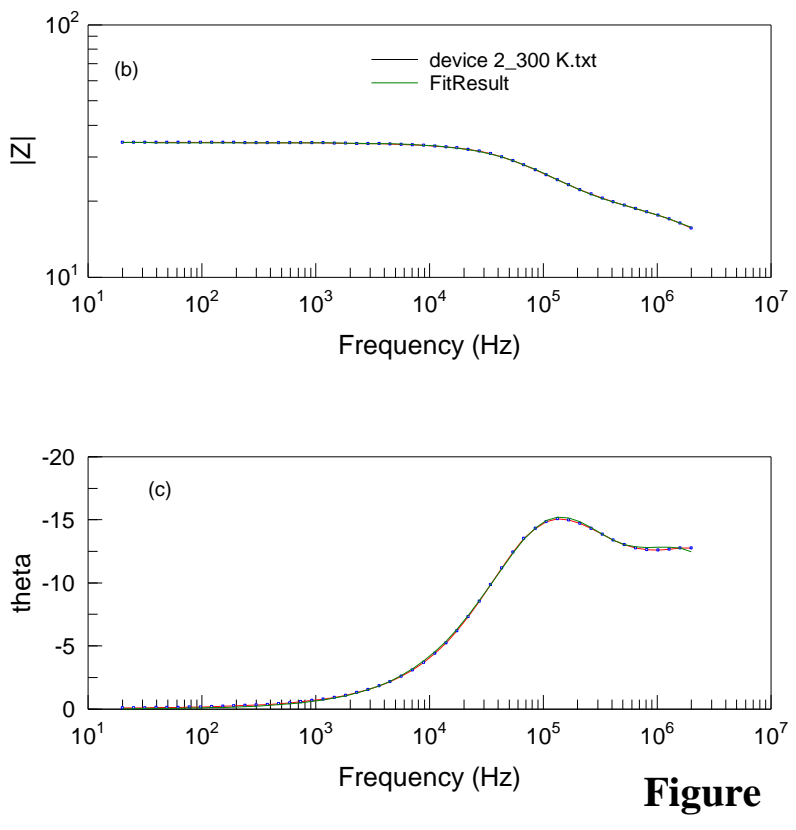

S1. Fitting of impedance spectra of Type B in (a) complex plane and (b and c) Bode plot 

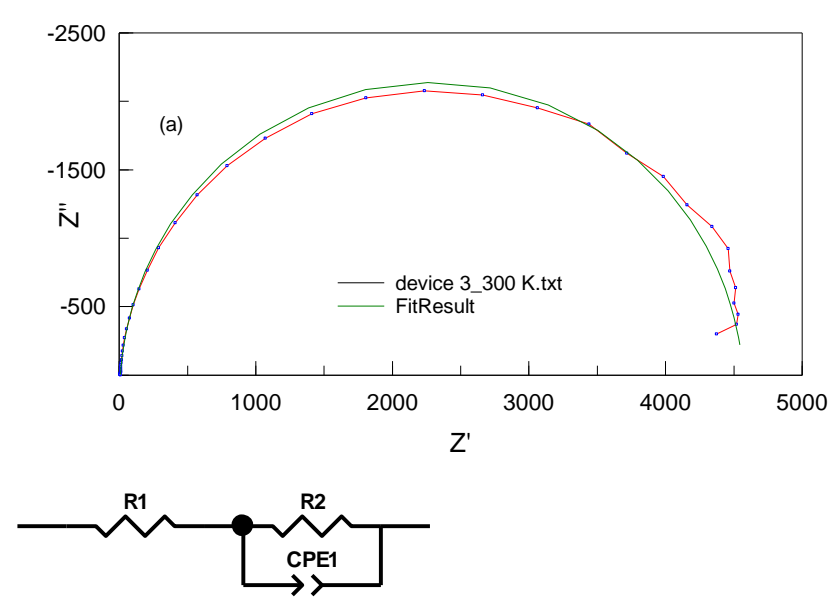

\begin{tabular}{|c|c|c|c|c|}
\hline Element & Freedom & $\underline{\text { Value }}$ & Error & Error \% \\
\hline $\mathrm{R} 1$ & Free(+) & $\overline{7.796}$ & $\overline{0.070141}$ & $\overline{0.8997}$ \\
\hline $\mathrm{R} 2$ & Free(+) & 4561 & 29.405 & 0.64471 \\
\hline CPE1-T & Free(+) & 1.0423E-07 & 2.0512E-09 & 1.968 \\
\hline CPE1-P & Free(+) & 0.9589 & 0.0016835 & 0.17557 \\
\hline
\end{tabular}
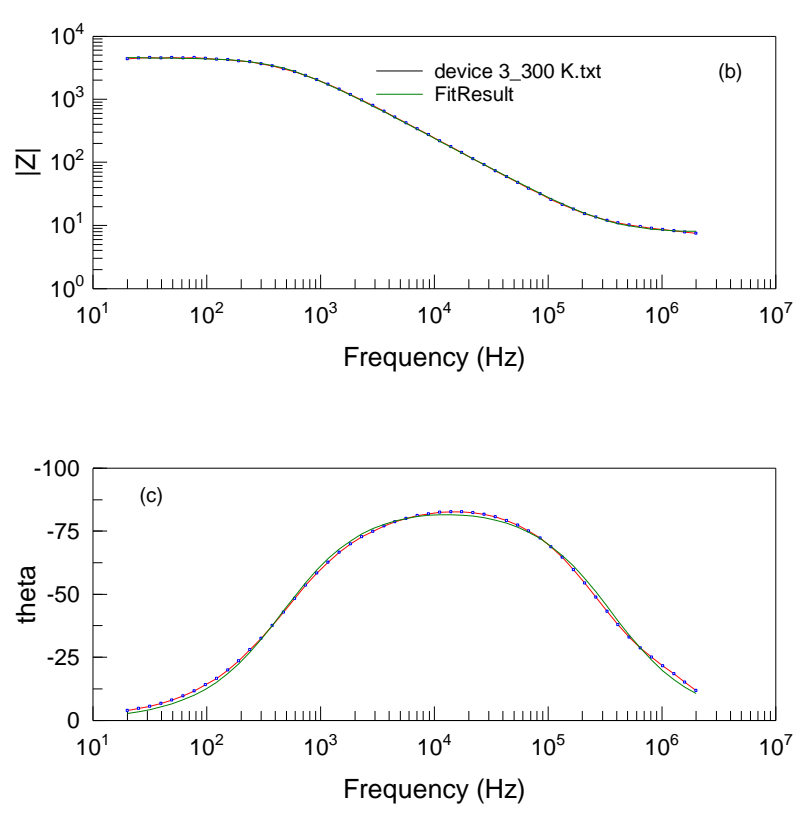

Figure S2. Fitting of impedance spectra of Type $\mathrm{C}$ in (a) complex plane and (b and c) Bode plot

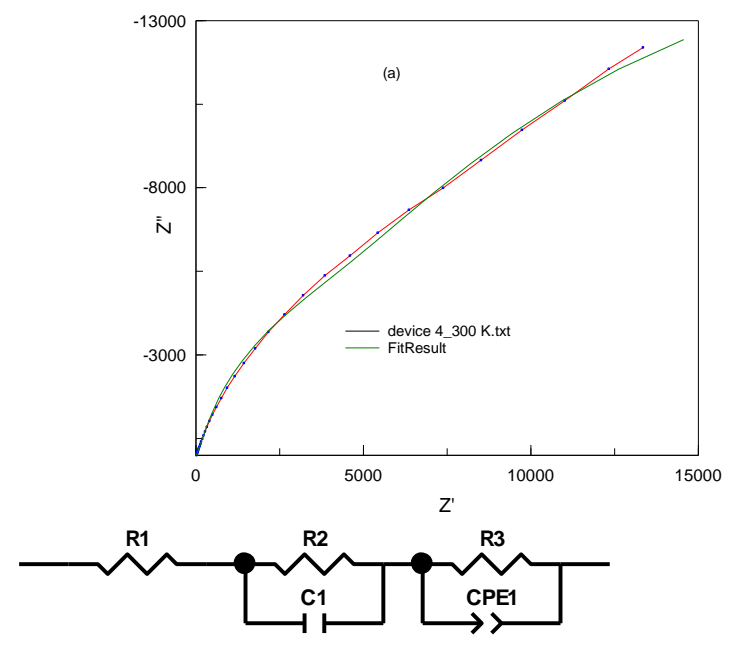

\begin{tabular}{|c|c|c|c|c|}
\hline Element & Freedom & $\underline{\text { Value }}$ & Error & Error \% \\
\hline $\mathrm{R} 1$ & Free(+) & 10.91 & 0.28613 & 2.6226 \\
\hline $\mathrm{R} 2$ & Free(+) & 2353 & 319.7 & 13.587 \\
\hline $\mathrm{C} 1$ & Free(+) & 2.9907E-07 & 2.5377E-08 & 8.4853 \\
\hline R3 & Free $(+)$ & 42909 & 4020 & 9.3687 \\
\hline CPE1-T & Free(+) & 1.2362E-06 & $9.651 \mathrm{E}-08$ & 7.807 \\
\hline CPE1-P & Free(+) & 0.74159 & 0.0055495 & 0.74832 \\
\hline
\end{tabular}
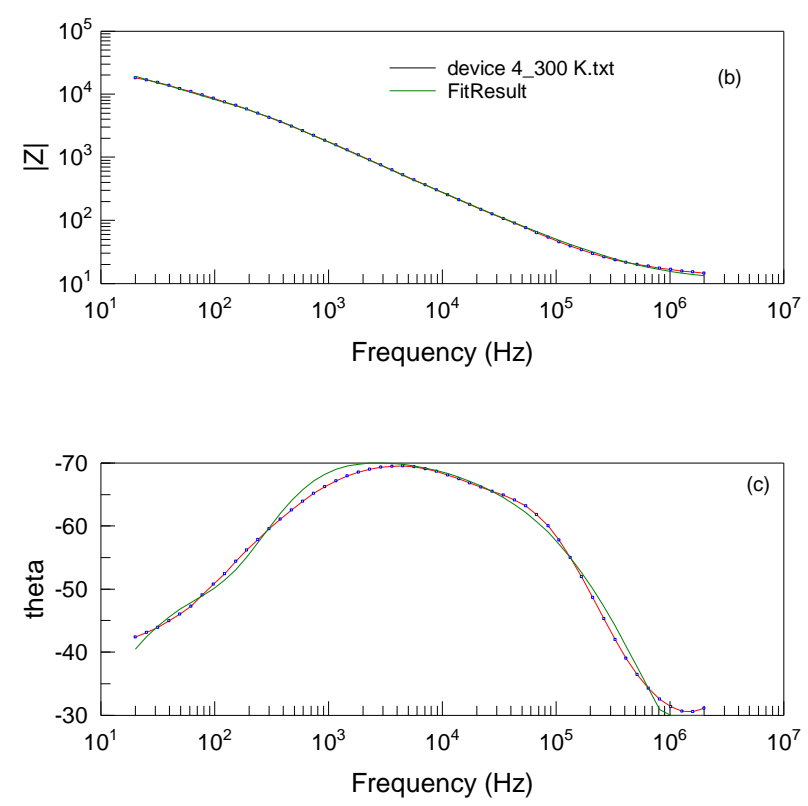

Figure S3. Fitting of impedance spectra of Type D in (a) complex plane and (b and c) Bode plot 

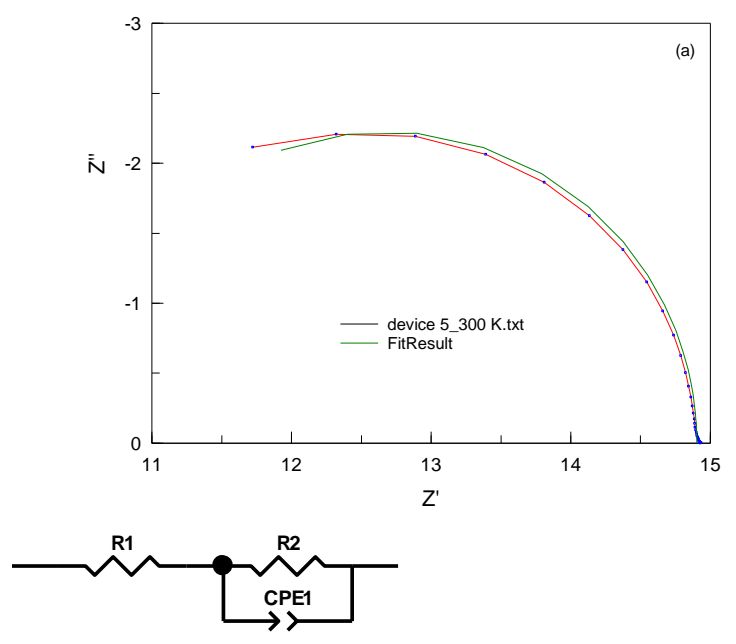

\begin{tabular}{|c|c|c|c|c|}
\hline Element & Freedom & Value & Error & Error \% \\
\hline $\mathrm{R} 1$ & Free(+) & 10.45 & 0.042439 & 0.40611 \\
\hline $\mathrm{R} 2$ & Free(+) & 4.451 & 0.043399 & 0.97504 \\
\hline CPE1-T & Free(+) & 2.5566E-08 & 1.9444E-09 & 7.6054 \\
\hline CPE1-P & Free(+) & 0.99968 & 0.0058422 & 0.58441 \\
\hline
\end{tabular}
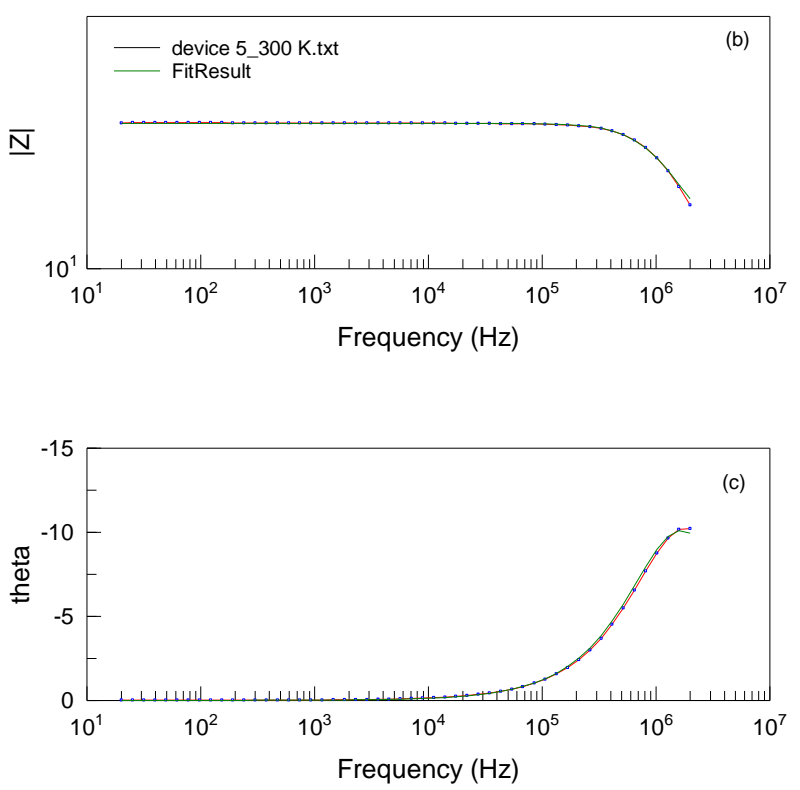

Figure S4. Fitting of impedance spectra of Type A' in (a) complex plane and (b and c) Bode plot
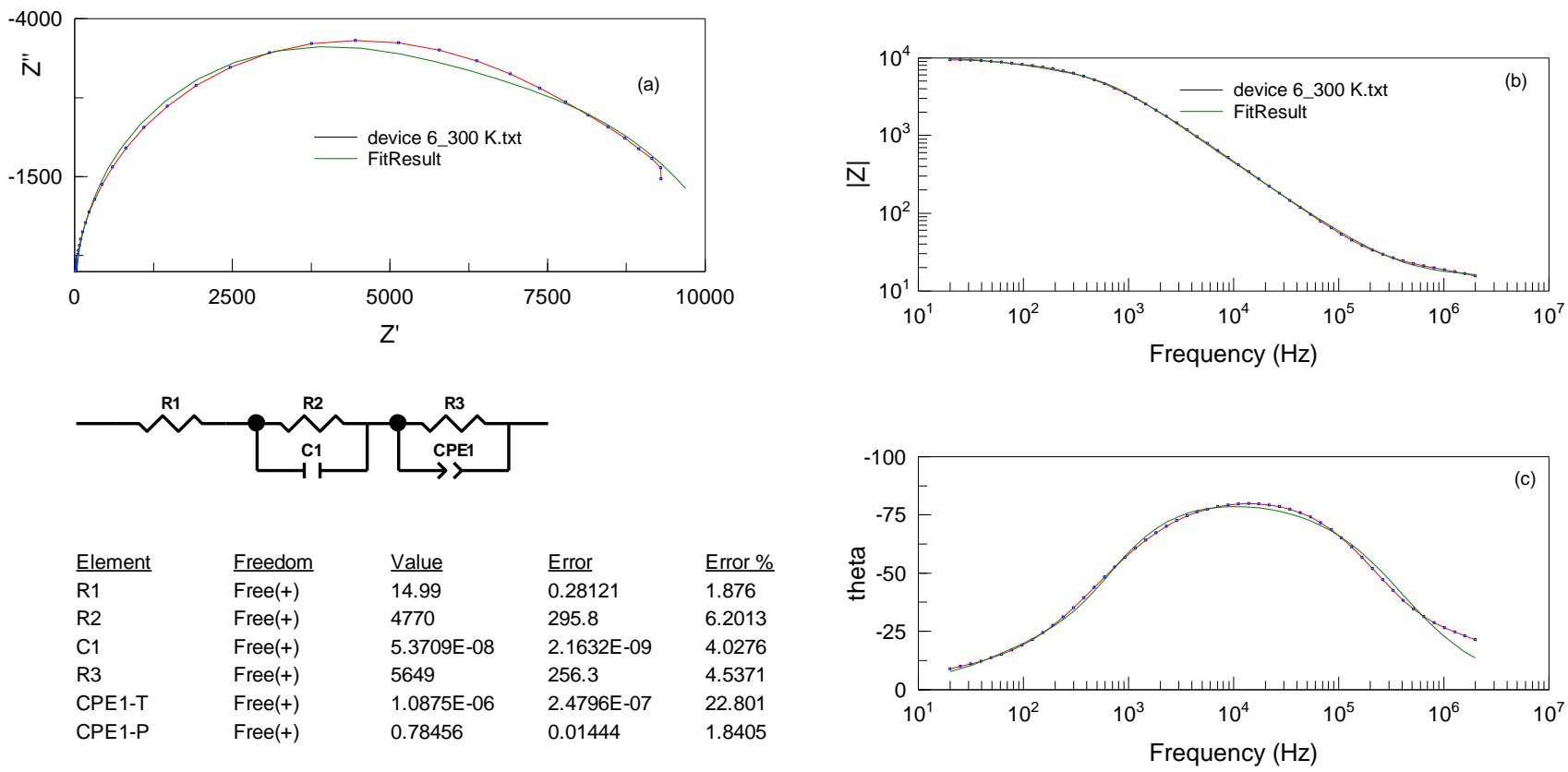

Figure S5. Fitting of impedance spectra of Type B' in (a) complex plane and (b and c) Bode plot 

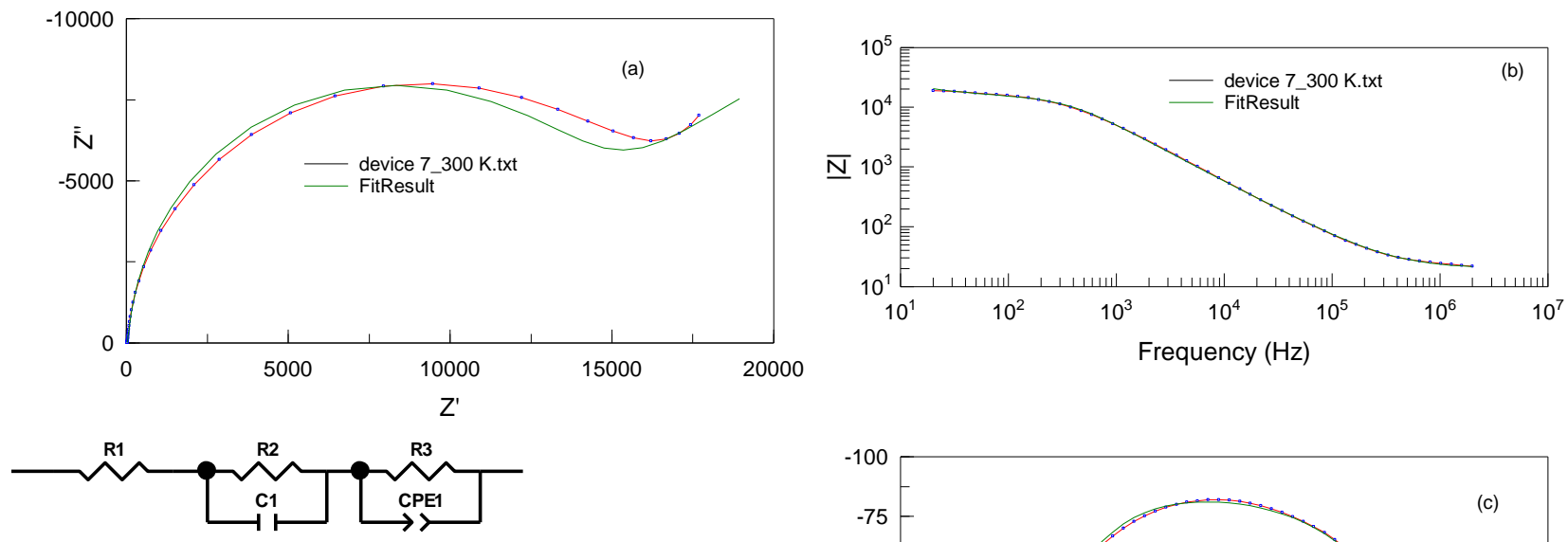

\begin{tabular}{|c|c|c|c|c|}
\hline Element & Freedom & $\underline{\text { Value }}$ & Error & Error \% \\
\hline $\mathrm{R} 1$ & Free(+) & 19.54 & 0.28341 & 1.4504 \\
\hline $\mathrm{R} 2$ & Free(+) & 13417 & 243.42 & 1.8143 \\
\hline $\mathrm{C} 1$ & Free $(+)$ & 3.447E-08 & $3.8178 \mathrm{E}-10$ & 1.1076 \\
\hline R3 & Free(+) & 35463 & 9083.1 & 25.613 \\
\hline CPE1-T & Free(+) & 3.301E-06 & 3.6434E-07 & 11.037 \\
\hline CPE1-P & Free(+) & 0.70324 & 0.0079718 & 1.1336 \\
\hline
\end{tabular}

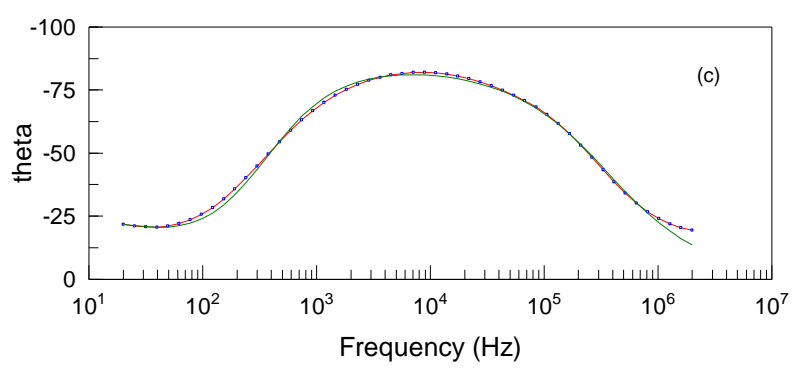

Figure S6. Fitting of impedance spectra of Type $C^{\prime}$ in (a) complex plane and (b and c) Bode plot
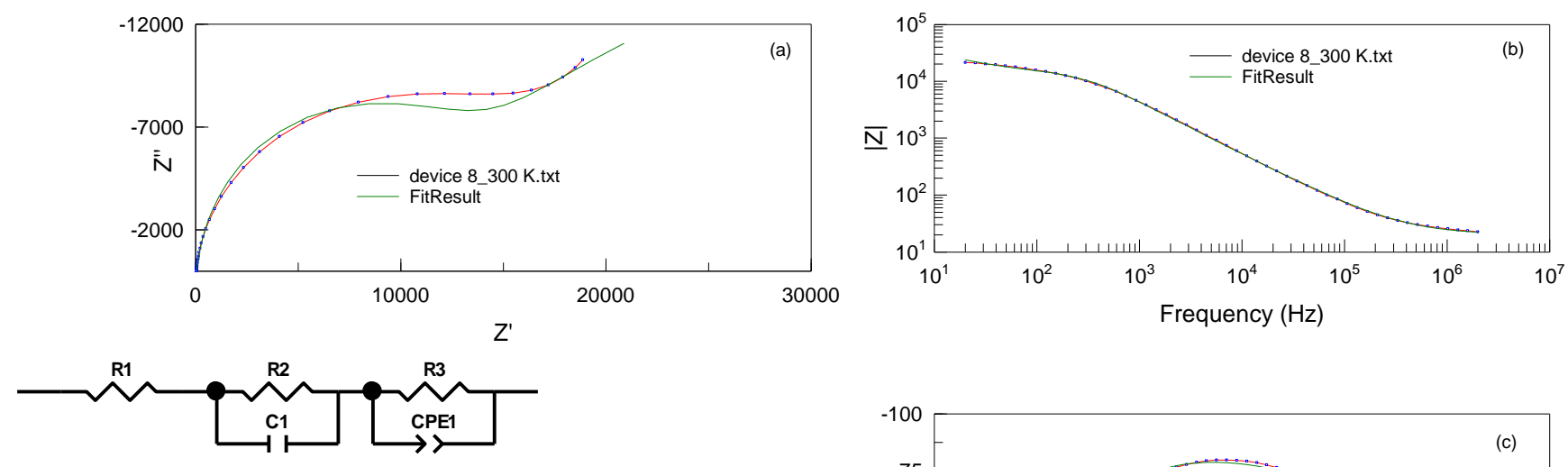

\begin{tabular}{|c|c|c|c|c|}
\hline Element & Freedom & $\underline{\text { Value }}$ & Error & Error \% \\
\hline $\mathrm{R} 1$ & Free(+) & 19.93 & 0.33996 & 1.7058 \\
\hline $\mathrm{R} 2$ & Free(+) & 11770 & 325.55 & 2.7659 \\
\hline $\mathrm{C} 1$ & Free(+) & 4.5609E-08 & $7.593 E-10$ & 1.6648 \\
\hline R3 & Free(+) & 43854 & 6927 & 15.796 \\
\hline CPE1-T & Free(+) & 1.8373E-06 & 1.7413E-07 & 9.4775 \\
\hline CPE1-P & Free(+) & 0.72101 & 0.0068005 & 0.94319 \\
\hline
\end{tabular}

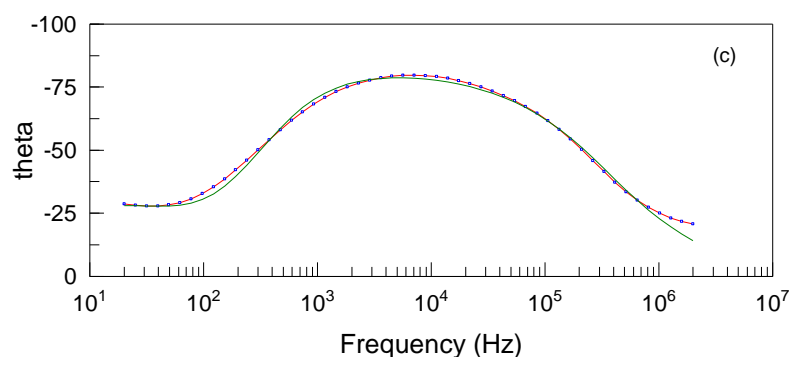

Figure S7. Fitting of impedance spectra of Type D' in (a) complex plane and (b and c) Bode plot 

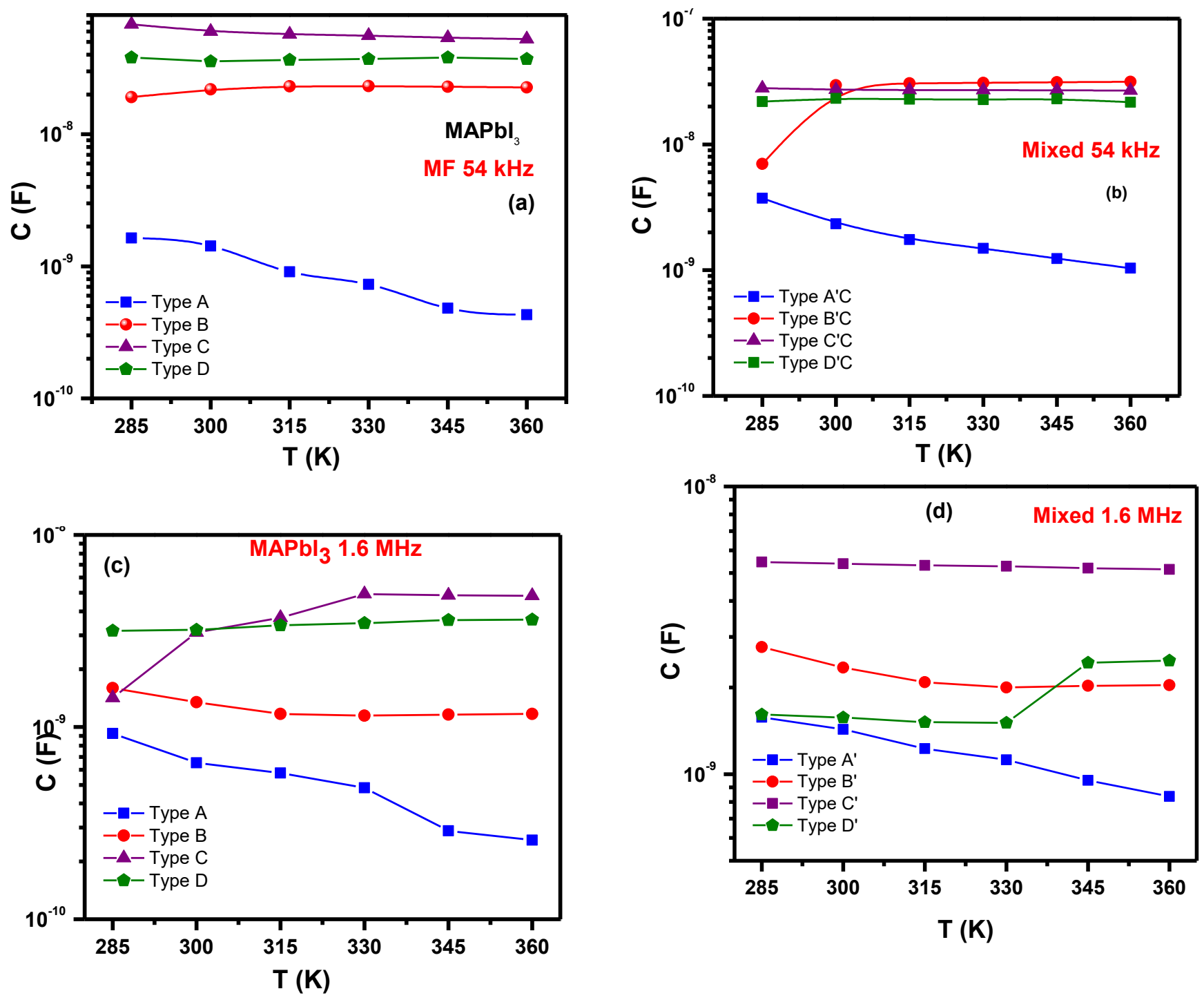

Figure S8. Temperature dependence of ( $a, b)$ Intermediate frequency and $(c, d)$ high frequency capacitance of all devices. 


\section{S2. Evaluation of activation energy}
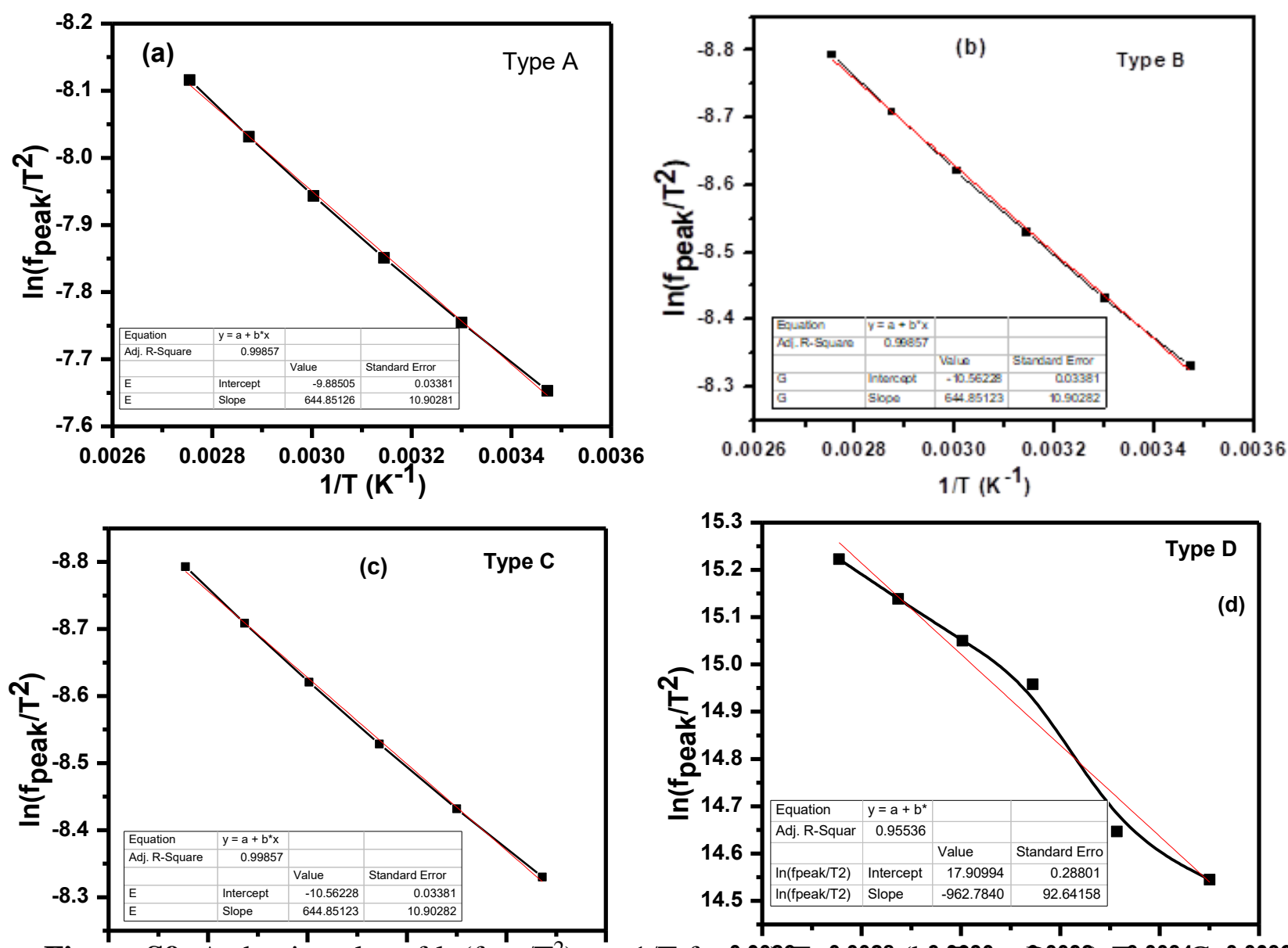

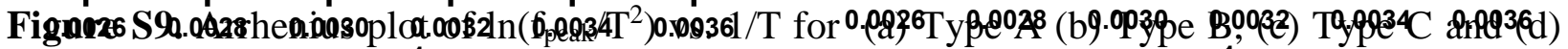
Type D. 

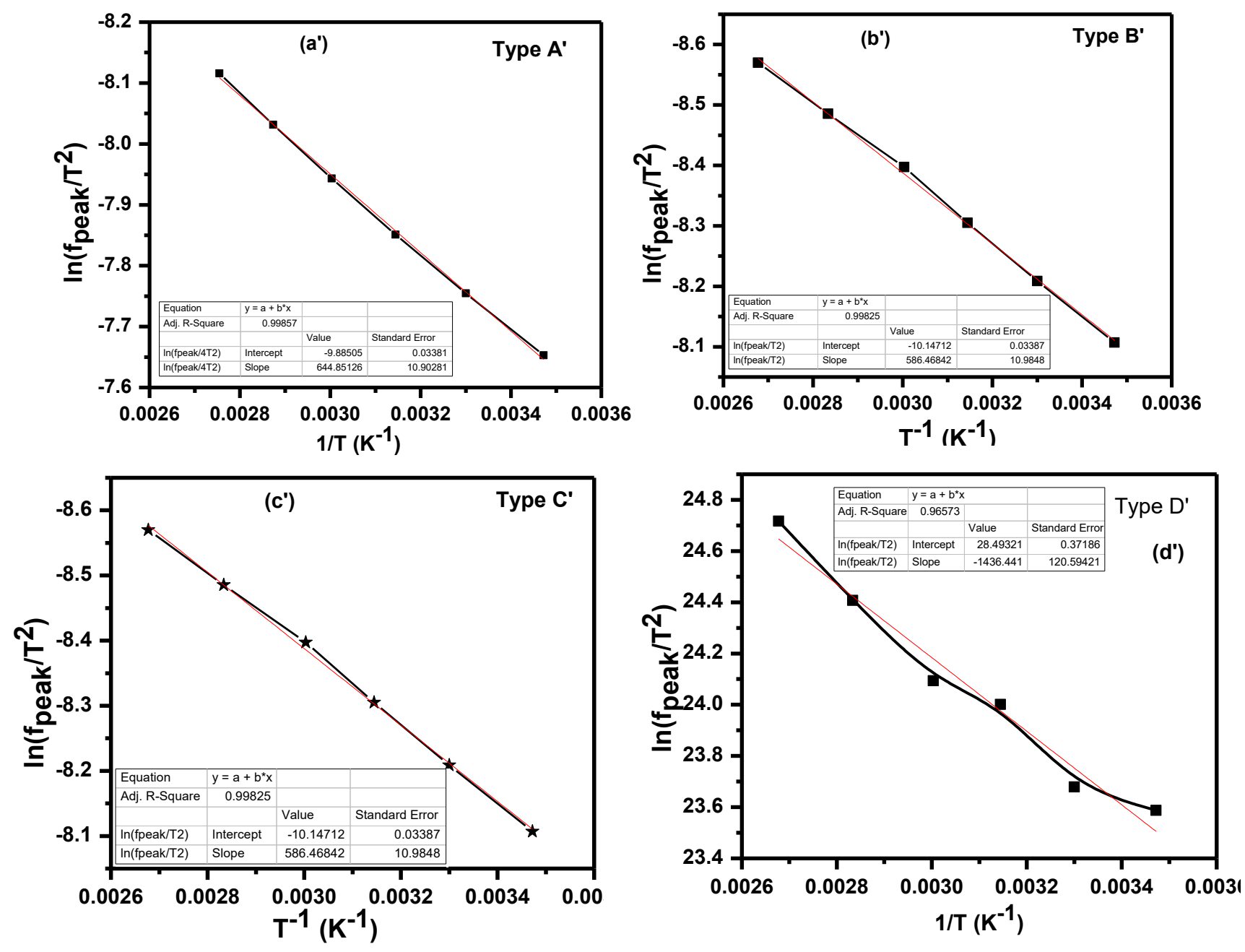

Figure S10. Arrhenius plot of $\ln \left(f_{\text {peak }} / T^{2}\right)$ vs. $1 /$ T for (a') Type A' (b') Type B', (c') Type C' and (d') Type D'.

The density of state $\mathrm{N}_{\mathrm{C}}$ was estimated from the relation

$$
N_{C}=\frac{v_{o}}{v_{t h} \sigma_{n}}
$$

where $v_{o}$ is attempt to escape frequency (ATEF), $v_{\text {th }}$ is the root mean square thermal velocity of electrons and equal to $v_{t h}=\sqrt{\frac{3 k_{B} T}{m}}=1.17 \times 10^{7} \mathrm{~cm} / \mathrm{s}$ at $300 \mathrm{~K}$, and $\sigma_{\mathrm{n}}$ is the capture cross section of trap for both electron and hole $\sim 1 \times 10^{-14} \mathrm{~cm}^{-2}$ [ Y. Wang, Z. Xia, J. Liang, X. Wang, Y. Liu, C. Liu, S. Zhang and H. Zhou, Semicond. Sci. Technol. 30 (2015) 054004]. 
The value of $\mathrm{ATEF}^{v_{o}}$ was estimated from the relation

$v_{0}=\xi T^{2}$

The intercept of Arrhenius plot, $\ln \left(\frac{f_{\text {peak }}}{T^{2}}\right) v s \cdot \frac{1}{T}$ shown in above Figures give the value of $\ln (\xi)$.

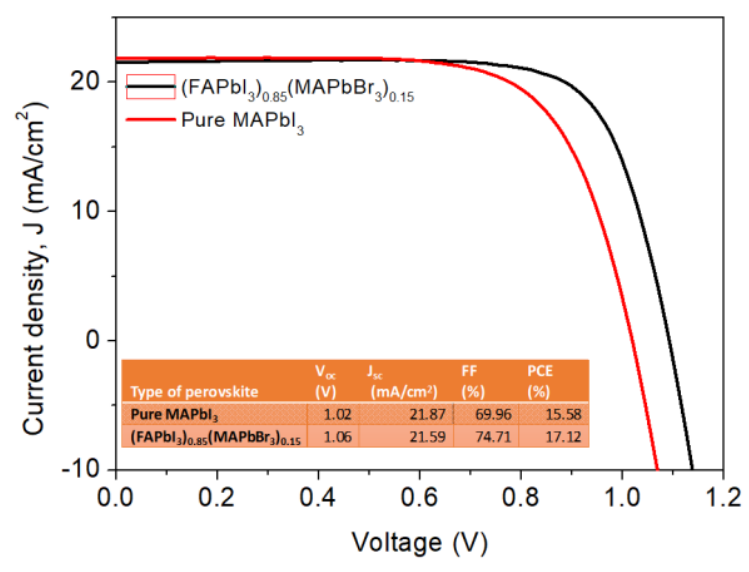

Fig.S11: Representative $J-V$ curves for fabricated solar cells. 